\title{
College adjustment experiences of first -year students: Retired athletes, non -athletes, and current varsity athletes
}

John R. Lubker

West Virginia University

Follow this and additional works at: https://researchrepository.wvu.edu/etd

\section{Recommended Citation}

Lubker, John R., "College adjustment experiences of first -year students: Retired athletes, non -athletes, and current varsity athletes" (2006). Graduate Theses, Dissertations, and Problem Reports. 3446.

https://researchrepository.wvu.edu/etd/3446

This Dissertation is protected by copyright and/or related rights. It has been brought to you by the The Research Repository @ WVU with permission from the rights-holder(s). You are free to use this Dissertation in any way that is permitted by the copyright and related rights legislation that applies to your use. For other uses you must obtain permission from the rights-holder(s) directly, unless additional rights are indicated by a Creative Commons license in the record and/ or on the work itself. This Dissertation has been accepted for inclusion in WVU Graduate Theses, Dissertations, and Problem Reports collection by an authorized administrator of The Research Repository @ WVU.

For more information, please contact researchrepository@mail.wvu.edu. 
College Adjustment Experiences of First-Year Students:

Retired Athletes, Non-Athletes, and Current Varsity Athletes

John R. Lubker, Ed.S.

Dissertation submitted to the School of Physical Education

at West Virginia University

in partial fulfillment of the

requirements for the degree of

Doctor of Education

in

Physical Education

Edward Etzel, Ed.D., Chair

Jack Watson, Ph.D.

Andrew Ostrow, Ph.D.

Stan Cohen, Ph.D.

Anita Mayer, M.A.

Lisa Hamilton, Ph.D.

Morgantown, West Virginia

2006

Keywords: College Adjustment, Athletic Identity, Disengagement from Sport 


\section{ABSTRACT \\ College Adjustment Experiences of First-Year Students: Retired Athletes, Non-Athletes, and Current Varsity Athletes}

John R. Lubker

Research investigating the disengagement experiences of high school athletes and their subsequent adjustment to the college environment has been limited at best. The purpose of this investigation was to examine the differences in college adjustment patterns and reported athletic identity of first-year college males and females $(N=317)$. Three status groups were used in this study: retired high school senior athletes $(n=125)$, high school senior non-athletes $(n=106)$, and current college varsity athletes $(n=78)$. Significant differences were observed between the three athletic status groups where retired high senior athletes had significantly different athletic identity scores than both college athletes and high school non-athletes. Freshman females reported higher academic adjustment than males in the total sample. For retired high school senior athletes, both gender and athletic identity differences were found. For this group, there were differences in college adjustment related to the nature of retirement decision and level of social support. Potential applications of findings and future directions related to research are explored. 


\section{DEDICATION}

To my wife, Kat - You have made this part of our journey so much fun! Your unconditional support and love has made this mountainous project achievable. I am so lucky to have found such a saint. I LOVE YOU!

To my parents, Jack and Kathy - Your cheers for me have always been the loudest! Your help, love, and guidance have been such a positive force in my life. Thank you both for everything and I mean everything!

To my mentor, David M. Moss - Without your inspiration, I would be in a small cubicle in a big city longing for something better. Your guidance helped me find my calling...I can never thank you enough! 


\section{ACKNOWLEDGEMENTS}

There are many people I would like to thank because without their guidance this project would not have been dreamed up or realized. Thank you all!

I would first like to thank my advisor and committee chair, Dr. Ed Etzel. Your sage-like guidance was such a blessing. It helped me grow as a person and as a professional and I feel so confident in my ability to mentor my own students. Thank you also for the numerous cups of coffee and music on loan, they really helped me get through this!

I would like to thank Dr. Jack Watson for his tireless editing of my document. Jack, you really have a gift that is absent in my DNA. Without your keen eye, my document would be an absolute mess! Your constant humor never let me take myself to seriously as well keeping my stress at a manageable level. Remember, there is karma in this world and one day you'll get that ace!

I would like to thank Dr. Andrew Ostrow for his mentorship in the project. You are a consummate professional and it is an honor to have you on my committee. Unfortunately, the future generations will not have the psychometric savvy that you instilled in me, but believe me, my students will!

I would like to thank Dr. Stan Cohen for his statistical guidance, especially in the planning phase of this project. Your help upfront let everything else fall into place. Also, I want to thank you for being the most enjoyable, informative, and difficult stats professor I have ever had. It was a pleasure being your student!

I would like to thank Anita Mayer for her belief in the beneficial nature of my project and letting me hang around the UASC trying to find participants. Without your workshop students and your knowledge of college adjustment, this project would have never been seen to fruition. You were such an important part of this committee, thank you for everything!

I would like to thank Dr. Lisa Hamilton for her help in seeing how this project could be applied to living, breathing college freshmen. Your take on how the information gained from this project has really opened my eyes to all the possibilities surrounding it. Also, a huge thank you for stepping up in the bottom of the ninth and sacrificing your personal time to helping me out as a member of this committee!

A special thank you to Paul Downey for being in the trenches with me on this project. There has never been a more applicable situation for the "You scratch my back, I'll scratch yours" quote. I know that eventually we will be rolling in the dough once we have developed our own adjustment to college scale!

Thank you to all my friends in the WVU Sport \& Exercise Psychology program. You have made the last four years some of the best I have ever experienced! 


\section{TABLE OF CONTENTS}

\section{Page}

$\begin{array}{ll}\text { Introduction } & 1\end{array}$

$\begin{array}{lr}\text { Method } & 6\end{array}$

$\begin{array}{ll}\text { Participants } & 6\end{array}$

$\begin{array}{ll}\text { Instrumentation } & 7\end{array}$

$\begin{array}{ll}\text { Pilot Research } & 8\end{array}$

$\begin{array}{ll}\text { Procedures } & 9\end{array}$

$\begin{array}{ll}\text { Results } & 10\end{array}$

$\begin{array}{ll}\text { Sport Participation and Gender on Athletic Identity } & 11\end{array}$

$\begin{array}{ll}\text { Athletic Status and Gender on College Adjustment } & 12\end{array}$

Athletic Identity and Gender on College Adjustment for RHSAs 12

Correlation of Divestment and College Adjustment for Male and Female RHSAs 13

Descriptive Factors on College Adjustment 13

$\begin{array}{ll}\text { Discussion } & 15\end{array}$

College Freshmen Level of Athletic Identity and Overall Adjustment 16

$\begin{array}{ll}\text { Retired High School Senior Athlete College Adjustment } & 17\end{array}$

Role of Social Support and Choice in Retirement on College Adjustment 19

$\begin{array}{ll}\text { Limitations } & 21\end{array}$

$\begin{array}{ll}\text { Future Directions } & 23\end{array}$

$\begin{array}{ll}\text { References } & 26\end{array}$

$\begin{array}{ll}\text { Tables } & 32\end{array}$

$\begin{array}{ll}\text { Appendices } & 35\end{array}$ 
Appendix A - Demographic Questionnaire 35

Appendix B - Athletic Identity Measurement Scale (AIMS) 39

Appendix C - Retrospective Athletic Identity Scale (R-AIMS) 41

Appendix D - Review of Literature $\quad 46$

Appendix E - Review of Literature References $\quad 68$ 


\section{LIST OF TABLES}

Page

Table 1 - Retired Athletes level of Identity and Adjustment to College

Table 2 - Correlation Matrix of Divestment and SACQ Subscales by Gender for RHSAs 33

Table 3 - Retired Athletes Decision to Retire and Adjustment to College 


\section{Introduction}

This year in the United States, men’s high school football, basketball, baseball, hockey and soccer combined to provide the chance for over 2.3 million athletes to participate in sport (NCAA, 2006). This number drastically declines from high school to approximately 35,000 college freshman roster positions, resulting in an average of only about 2 high school athletes out of every 100 eventually having the chance to play at the collegiate level (NCAA, 2006). These numbers indicate that playing at the collegiate level is quite an accomplishment and that a large percentage of college-bound high school athletes, who may still consider themselves athletes, disengage from scholastic sport at roughly the same time as they transition into college life.

“A transition can be said to occur if an event or non-event results in a change in assumptions about oneself and the world thus requires a corresponding change in ones behavior” (Schlossberg, 1981, p. 5). Various theories try to explain transitional experiences such as individual variability theory (Neugarten 1979), lifespan theory, (Danish, 1981), stage theory (Erikson, 1950), and transitional theory (Schlossberg, 1981). Although useful, transitional theory does not seem to fully capture the experiences of high school students transitioning to college. To obtain a richer picture of this experience, developmental task models (e.g., Chickering, 1981; Farnsworth, 1966; Havighurst, 1952; Medalie, 1981) should be considered. These developmental models help portray the general challenges young people face when making the transition from adolescence to adulthood . Particularly appropriate for understanding the challenges of first year students, Medalie’s (1981) “mini-life cycle” model describes the freshman year as a period of divestment from old roles and investment into the new roles of college life. This experience often includes mourning the losses of growing up, saying goodbye to old support systems, making new attachments with others, and coping with the responsibilities of being a college student. The 
quality of an individual's developmental experiences depends on how successful these tasks are met (Medalie, 1981). For that reason, the first year of college is a very important time for an individual to become independent and grow as a person.

The freshman year of college is usually acknowledged as a stressful time of social and academic adjustment (Oppenheimer, 1984). During this period, first-year students face many social challenges such as moving away from home and the support system found there as well as intellectual challenges (e.g., more demanding coursework) (Dunkel-Schetter \& Lobel, 1990; Sher, Wood, \& Gotham, 1996). First year transition can be filled with emotional disturbances which include loneliness, homesickness, and friend sickness (Morris, 1997; Paul \& Brier, 2001), grief (Vickio, 1990) and substance abuse/alcohol-related risk behaviors (Hildebrand, Johnson, \& Bogle, 2001). Martin, Swartz-Kulstad, and Madison (1999) identified three variables that may impact first-year emotional distress: 1) social (e.g., parental influences, social adjustment); 2) personal-emotional (e.g., emotional adjustment, coping style); and 3) institutional (i.e., attachment to the institution). Baker and Siryk (1989) proposed that these factors can help predict adjustment early in a college career.

The combined impact of transition and disengagement from sport can further complicate the adjustment of first semester college students and may also affect their retention. Taken together, these complex phenomenon may diminish self-concept, challenge one's felt sense of being an athlete, and elicit emotional responses usually associated with college and elite athlete disengagement (Blinde \& Stratta, 1992; Sparkes, 1998).

Sport disengagement typically results from one of three causes: 1) deselection process; 2) injury; or 3) age (Ogilvie \& Howe, 1986). In high school and college disengagement can occur for reasons such as graduation, deselection, dropping out of school, or choosing to focus on other 
roles (Danish, Owens, Green, \& Brunelle, 1997). Some research has shown that disengagement can have a negative impact on overall functioning, and can be linked to unhealthy behaviors and emotions such as alcohol and drug abuse, anger, anxiety, and depression (Mihovilovic, 1968; Sinclair \& Orlick, 1993). This appears to be most common when a career-ending injury or forced retirement has occurred (Chan \& Grossman, 1988; Leddy, Lambert, \& Ogles, 1994). While most research in this area has been conducted with elite and college athletes, disengagement from sport at the high school level may elicit similar responses.

Disengagement can also bring about positive feelings such as relief (Blinde \& Greendorfer, 1985), a re-establishment of more traditional roles and lifestyle (Allison \& Meyer, 1988), and a sense of improved life satisfaction (Curtis \& Ennis, 1988). Mediators of the disengagement process may include coping strategies (e.g., finding other areas of meaningful interest and endeavor), identification with the role of an athlete, pre-retirement planning, and social support (Pearson \& Petitpas, 1990; Taylor \& Ogilvie, 2001). In particular, social support has been cited in the literature as key to making a positive career transition (Grove, Lavallee, \& Gordon, 1997; Swain, 1991; Werthner \& Orlick, 1986).

Ogilvie and Howe (1986) suggested that disengagement from athletics and the ensuing transition can be hindered when an athlete's sense of self is linked to the athletic role (i.e., a strong athletic identity). Athletic identity has been defined as the extent to which a person identifies with the role of an athlete (Brewer, Van Raalte, \& Linder, 1993). Accordingly, an individual with a strong athletic identity may be inclined to interpret an event (e.g., failing a course) relative to its impact on athletic functioning (e.g., being declared ineligible) to a greater degree that an individual with a weak athletic identity would (e.g., not getting into graduate school) (Brewer et al., 1993). 
At first glance, possessing a strong athletic identity can have its benefits for those in transition. However, the literature, albeit limited, (Blinde \& Greendorfer, 1985; Brewer, et al., 1993), suggests that while there are benefits of having a strong, well-developed, athletic identity there are potential risks. Benefits include the development of a positive self-image through sports participation (McPherson, 1980), a positive effect on athletic performance (Werthner \& Orlick, 1986), and can aid in the maintenance of exercise behaviors throughout the lifespan (Anderson \& Cychosz, 1994). In contrast, some of the potential risks of a strong athletic identity include emotional difficulties encountered in disengagement from sport through deselection, serious injury, and retirement (Person \& Petitpas, 1990). Individuals whose identity is strongly influenced by the athletic role may lack the necessary social support systems for a smooth transition after retirement (Ballie \& Danish, 1992; Taylor \& Ogilvie, 2001). Athletic identity may also be positively correlated to the duration of psychological adjustment needed as a result of the deselection process (Brewer, 1993; Grove et al., 1997).

Coakley (1983) believed adjustment difficulties can occur when athletes have a) been seriously restricted in personal development; b) relationships restricted to only other athletes in sport-related activities; c) little social and emotional support outside the realm of their athletic prowess; d) little access to positive role-models or activities outside the arena of sport; and e) a lack of access to resources that do not involve sport. Applying Schlossberg's (1981) transition model to the experiences of disengaging athletes, Pearson and Petitpas (1990) suggested that the process can be challenging for athletes who: a) have exclusively based their identity on athletic performance; b) lack prior experience with similar transitions; c) have limited ability to adapt to change; d) have limited ability to form and maintain supportive relationships; and e) deal with transition lacking the material and emotional resources needed. 
There has been little research on the topic of the transition/disengagement experiences and possible subsequent adjustment reactions of high school athletes moving to the college environment. This lack of research may reflect the view that high school athletes do not invest as much as college or elite athletes in the athletic role to the detriment of other, long-term (e.g., career) roles. Pearson and Petitpas (1990) suggested, but never provided, concrete evidence for an expectation of:

A considerable amount of overlap between the developmental patterns and experiences of non-athletes and persons whose athletic endeavors are only a small aspect of their life focus. However, as a person's identity and activity increasingly center on athletics, the likelihood increases of encountering developmental challenges and events that are unique, or are substantially different from those of other persons not engaged in careers centered on performance that demands high levels of physical excellence. (p. 7)

Blinde and Greendorfer (1985) believed this line of research has not accurately portrayed the experiences of the transitioning athlete. This belief stems from most of the research being conducted with college, elite, and professional athletes, limiting the generalizability to the entire population of transitioning athletes. Also, white, male athletes have been the focus of most studies to date. Sher and his colleagues (1996) suggest that to enhance college student well-being and increase retention there needs to be a focus on whether specific student groups experience distress more acutely than others. Incorporating this into the ideas of Blinde and Greendorfer (1985), it would seem useful to move away from generalizing disengagement and transitory experiences and conduct research that specifically examines the experiences of these groups.

The five purposes of this research study were to: 1) investigate the possible differences in reported levels of athletic identity between disengaged high school senior athletes, high school senior non-athletes, and first-year college athletes; 2) investigate the possible differences between the college adjustment experiences of disengaged high school senior athletes, high school senior non-athletes, and first-year college athletes; 3) understand how identification with 
athletic role might impact adjustment experiences of retired high school senior athletes; 4) understand how divestment from the athletic role may be related to adjustment to college for retired high school senior athletes; and 5) determine how past athletic experiences may predict adjustment to college for retired high school senior athletes.

Five, gender-specific hypotheses were generated. Those hypotheses were: 1) retired high school senior athletes (RHSAs) would have a more well developed athletic identity than those who did not participate in sport their senior year (NAs) and current varsity athletes (CVAs) would report the highest level of athletic identity of all three groups; 2) CVAs would have a more difficult time adjusting to college than RHSAs, in turn RHSAs would have a more difficult time adjusting to college than NAs; 3) RHSAs who had a high level of athletic identity would have more difficulty adjusting to college during the first semester than those with moderate and weak athletic identities; 4) RHSAs who had not divested from sport (i.e., retrospective athletic identity score subtracted from current athletic identity score) would have more difficulty adjusting to college than those who had divested; and 5) the descriptive variables of intramural sports participation, recreation center use, perceived level of social support, expectation to play in college, being recruited to play in college, being offered a scholarship to play in college, and control over the decision to retire would be predictive of college adjustment for RHSAs.

Method

\section{Participants}

The sample consisted of 165 male and 152 female $(N=317)$ college freshmen, ages 17 ( $n=37)$ and 18-19 ( $n=280)$, who attended a large sized land grant university. The sample was principally Caucasian ( $n=275)$, with a small representation of minority students: Asian $(n=3)$, African-American ( $n=25)$, Latino $(n=5)$, and other $(n=7)$. The present sample mirrored the total 
university demographic profile to include high school non-senior athletes $(n=106)$, senior high school athletes $(n=133)$, and current college freshman athletes $(n=78)$. High school and college sports played by athletes in this sample included: baseball, basketball, cheerleading, crew, cross country, dance, diving, field hockey, football, golf, gymnastics, hockey, lacrosse, rifle, soccer, softball, swimming, tennis, track, volleyball, and wrestling.

\section{Instrumentation}

Four instruments were administered to participants. A demographic questionnaire developed by the principal investigator (see Appendix A) was used to assess: race, gender, proposed major, plans for joining the Greek system, intramural sports participation, recreation center use, years of sport participation in high school, starter on high school team, number of years played in high school, expectation to play in college, being recruited to play in college, being offered a scholarship to play in college, and decision to retire.

The Athletic Identity Measurement Scale (AIMS; Brewer \& Cornelius, 2001) was a seven-item, self-report, Likert-type (1-7) scale deigned to measure an individual's level of identification with the athletic role (see Appendix B). This version of the AIMS has been found to be internally consistent (alpha $=.81$ ). Test-retest reliability of the AIMS was reported to be .89 (Brewer \& Cornelius, 2001). The Retrospective Athletic Identity Measurement Scale (R-AIMS; developed by the principle investigator) was a seven-item, self-report scale with questions mirroring those of the AIMS but stated in the past tense. It was intended to measure the extent to which an individual identified with the athletic role from one year ago (see Appendix C). The Student Adaptation to College Questionnaire (SACQ; Baker \& Siryk, 1999) was designed to assess personal adjustment to college. The SACQ is a 67-item, self-report, Likert-type (1-9) questionnaire consisting of four subscales assessing the four facets of college adjustment: 
academic, social, personal-emotional, and attachment to the university (Baker \& Siryk, 1999). The ranges of internal consistency coefficients gathered in prior studies by subscale were: Academic Adjustment (.81-.90), Social Adjustment (.83-.91), Personal-Emotional (.77-.86), and Attachment (.85-.91) (Baker \& Siryk, 1999). The criterion validity of the SACQ has been supported in previous studies that have compared the SACQ scales and real-life behaviors linked to college transition to college. Significant correlations were found between the Academic Adjustment scale and freshmen GPA (.17 to .53), between the Personal-Emotional scale and use of campus counseling center (-.23 to -.27), and between the Attachment scale and attrition rate after one year of college (-.27 to -.41) (Baker \& Siryk, 1999).

Pilot Research

During the fall semester of 2004, the demographic questionnaire, AIMS, and SACQ were administered in a pilot study to assess if an individual's level of athletic identity, as influenced by high school sport participation, would be linked to adjustment to college life in the first semester of the freshman year. The sample consisted of freshman college students enrolled in a first-year orientation course $(N=175)$ who were retired high school senior athletes $(n=97)$ and prior high school senior non-athletes $(n=78)$. These students were enrolled at a large MidAtlantic University and registered for a freshman orientation class.

A 2 (gender) X 3 (athletic status) MANOVA comparing male and female retired high school senior athletes in low, medium, and high athletic identity groups revealed a main effect for gender on the academic, social, and attachment subscales that approached significance ( $p>$ .05). Positive correlations were found between the level of divestment (i.e., lowering of athletic identity between senior year of high school and freshman year of college) and both the social and attachment subscales of the SACQ approaching statistical significance $(p>.05)$. 
During the spring semester of 2005, the R-AIMS was piloted to investigate its ease of use, time completed, and appropriateness. Participants $(n=20)$ were asked to complete the AIMS and then to complete the R-AIMS five to ten weeks later. There were no statistically significant differences ( $p$ ’s $>.05$ ) between each of the corresponding seven questions that comprise both the AIMS and R-AIMS, indicating that athletes could display a high level of accuracy recollecting athletic identity from a previous time.

\section{Procedures}

Prior to collecting data, approval for this study was obtained from the Institutional Review Board for the Protection of Human Subjects. An informed consent letter was included in each assessment packet that explained that completing the assessment packet was a form of consent as well as the contact information of the principal investigator. Each participant was assigned an identification number prior to the administration of the assessment battery.

The assessment period for this study was during weeks nine and ten of the fall semester of 2006, three days after academic mid-term reports were issued to all students at the university. A randomized cluster sampling of students and college student-athletes was employed to achieve the desired approximated total sample size $(N=550)$ for the study. Data collected from a first year college student-athlete orientation course comprised the CVA group $(n=78)$ and was a sample of convenience with no incentive for inclusion in the study. Non-varsity athlete college students signed-up for the mandatory Undergraduate Academic Services Center (UASC) advising workshops ( $n=171$; approximate population of $N=3000$ ) or enrolled in two general first year college student orientation classes $(n=68)$ were a sample of convenience that comprised the RHSA and NA groups. In this study, all participants who did not play a varsity sport their senior year in high school were assigned to the NA group. For the RHSA/NA groups, a total of 448 
participants were sampled. However, due to missing data and non-traditional participants, only 317 participant's data were analyzed, representing $71 \%$ of the original sample. As an incentive for this sample group, a $\$ 100$ prize was awarded at random to one participant upon full completion of the assessment battery once the study had concluded. There were no reported significant differences between the workshop and general orientation course participants on the four subscales of the SACQ ( $p$ 's $>.05$ ) or the AIMS total score $(p>.05)$. Therefore, it was assumed that these two groups could be combined together for the analyses.

Prior to statistical analyses, each participant's total AIMS score was used to divide the male and female RHSA groups into six subgroups reflecting each participant's athletic identity score. These six subgroups consisted of 1) RHSA/high athletic identity/male; 2) RHSA/high athletic identity/female; 3) RHSA/medium athletic identity/male; 4) RHSA/medium athletic identity/female; 5) RHSA/low athletic identity/male; and 6) RHSA/low athletic identity/female. The medium athletic identity group was comprised of $+/-0.5$ standard deviation from the sample mean. The high athletic identity group consisted of scores greater than $+0.5 \mathrm{SD}$ of the sample mean and the low athletic identity group consisted of scores less than -0.5 SD of the sample mean. To achieve a composite divestment score for each RHSA participant, the AIMS was subtracted from the R-AIMS score.

\section{Results}

Data from 317 participants were analyzed. Six high school athletes reported only participating in their respective sport during their senior year of high school. Therefore, they were assigned to the NA group prior to statistical analyses, due to concerns relating to their reported level of athletic identity. All four subscales of the SACQ were employed in data analyses. 


\section{Sport Participation and Gender on Athletic Identity}

A 3 (RHSA/NA/CVA) X 2 (male and female) ANOVA was employed to measure the effect of sport participation on reported level of athletic identity (i.e., dependent variable was the AIMS total score). This statistical test was used to determine if male and female participants who reported participating in high school varsity sports during their senior year in high school differed from participants who reported not playing, and if those participants differed from current college varsity athletes on the extent of their athletic identity. Significant main effects were observed between both the gender and athletic status groups on total AIMS scores. Males $(M=31.77, S D=11.30)$ reported significantly higher AIMS scores than did females $(M=24.46$, $S D=11.69)$ in this sample $F(1,312)=18.27, p<.001, \eta^{2}=.056$. Significant differences were also observed between the three athletic status groups $F(2,312)=120.40, p<.001, \eta^{2}=.440$. Post-hoc analyses (Tukey) showed that all groups were statistically different from one another ( $p$ $<.001)$. Specifically, CVAs $(M=40.77, S D=6.68)$ reported significantly higher AIMS scores than the other two athletic status groups. RHSAs $(M=27.60, S D=9.98)$ were significantly different from NAs $(M=19.58, S D=9.25)$ on the AIMS. No significant interactions were found in this analysis. A follow-up independent sample t-test was conducted to investigate any possible differences between the RHSA ( $n=125 ; M=26.76, S D=9.87)$ sample and the national means for athlete $(n=1607 ; M=38.21, S D=6.54)$ and non-athlete $(n=529 ; M=24.45, S D=9.56)$ AIMS scores (Brewer \& Cornelius, 2001). Significant differences were found between the RHSA and athlete group $(t=-12.97, p<.001)$ as well as between the RHSA and non-athlete group $(t=2.62, p<.01)$ 


\section{Athletic Status and Gender on College Adjustment}

A 3 X 2 MANOVA was employed to determine if differences existed in the reported adjustment experiences of the three athletic status groups. The two independent variables were gender and the three athletic status levels (i.e., RHSAs, NAs, and CVAs). The dependent variables were participant's total scores on the four SACQ subscales. A significant main effect was observed between males and females on the academic adjustment subscale $F(1,316)=7.15$, $p<.05, \eta^{2}=.022$, with females $(M=46.36, S D=8.53)$ reporting a higher level of adjustment than males $(M=43.65, S D=9.47)$. No other significant differences or significant interactions between males and females were found. Specifically for the academic adjustment subscale, the effect size was small enough that the post hoc analysis was not found to be significant. Post-hoc analyses (Tukey) showed that the athletic status groups were not significant from each other ( $p>$ .05) on the four subscales of the SACQ.

Athletic Identity and Gender on College Adjustment for RHSAs

To determine if there were any significant relationships between the adjustment experiences of the six retired high school senior athlete subgroups, a 3 (H/M/L athletic identity) X 2 (male/female) MANOVA was employed. The four dependent variables were participant’s scores on the four SACQ subscales. A significant observed main effect was found between gender groups on the attachment to the university subscale $F(1,132)=4.63, p<.05, \eta^{2}=.035$ (see Table 1$)$. Female retired athletes $(M=49.07, S D=9.17)$ reported feeling significantly more attached to the university than male retired athletes $(M=45.62, S D=9.59)$. A significant main effect between the three AIMS groups was observed on the academic adjustment subscale, $F(2$, $132)=3.50, p<.05, \eta^{2}=.052$. The medium level athletic identity group $(M=42.65, S D=9.17)$ was significantly lower than both the low $(M=47.07, S D=9.85)$ and high $(M=46.88, S D=$ 
8.27) athletic identity groups. Analyses for the other SACQ subscales were not significant, nor were any significant interactions present. Post-hoc analyses revealed that the athletic identity groups were not significantly different from each other in relation to college adjustment $(p>$ $.05)$.

Correlation of Divestment and College Adjustment for Male and Female RHSAs

A correlation matrix was calculated to determine if there was a significant relationship between the divestment scores and the four SACQ sub-scale scores of male and female RHSAs (see Table 2). Divestment from athletics was measured by subtracting R-AIMS scores from current AIMS scores to gain a composite divestment score. No significant correlations were reported for any of the four SACQ subscales $(p>.05)$. The AIMS was negatively correlated with the SACQ subscales (-.002 to -.090) at insignificant levels $(p>.05)$ while the R-AIMS was positively correlated with the SACQ subscales (.020 to .122) at insignificant levels $(p>.05)$. Descriptive Variables on College Adjustment

A hierarchical regression analysis was conducted to examine the predictive qualities of certain athletic experience variables on the four SACQ subscale scores for the RHSA group. The seven independent variables were 1) intramural sports participation; 2) recreation center use; 3) perceived level of social support; 4) control over the decision to retire; 5) expectation to play in college; 6) being recruited to play in college; and 7) being offered a scholarship to play in college. The four dependent variables were the subscale scores of the SACQ. Predictors were analyzed in groups according to their relevance to the overall model of college adjustment. Only two predictors significantly contributed to the prediction models: 1) “decision to retire” and 2) level of perceived social support. Only “decision to retire” significantly contributed to the prediction of academic adjustment $F(2,120)=3.85, p<.05, \mathrm{R}^{2}=.061$. Both IVs contributed 
significantly to the prediction of social adjustment $F(2,120)=8.45, p<.01, \mathrm{R}^{2}=.13$. Only “decision to retire” contributed significantly to the prediction of personal-emotional adjustment $F(2,120)=8.45, p<.001, \mathrm{R}^{2}=0.12$. Both IVs contributed significantly to the prediction of attachment to the university $F(2,120)=8.35, p<.001, \mathrm{R}^{2}=.12$.

Due to the consistency in the results of the regression models for the RHSAs, follow-up analyses were conducted on the two variables that completed the model: 1) social support and gender and 2) “decision to retire” and gender. RHSAs were spilt into high ( $\mathrm{n}=100$; choosing 6-7 on perceived social support) and moderate ( $n=33$; choosing 3-5 on perceived social support) groups on the perceived social support variable to conduct a 2 (high social support/moderate social support) X 2 (male/female) MANOVA. The social support factor produced significant interactions for both the social $F(1,132)=6.07, p<.05, \eta^{2}=.045$ and attachment $F(1,132)=$ 6.60, $p<.05, \eta^{2}=.049$ subscales. On both subscales, the female retired athletes with high social support subscale scores reported adjusting better than the other groups (social: $M=50.00, S D=$ 8.90; attachment: $M=50.42, S D=8.60$ ). Females with moderate social support subscale scores displayed the lowest adjustment of the four groups (social: $M=40.80, S D=6.32$; attachment: $M$ $=41.00, S D=8.69)$.

A second 2 (decision to retire) X 2 (gender) MANOVA was conducted on the RHSA group to investigate the potential impact of the decision to retire on college adjustment. Significant interactions for the “decision to retire” groups were observed on all four of the SACQ subscales: 1$)$ academic $\left.F(2,120)=5.45, p<.01, \eta^{2}=.085 ; 2\right)$ social $F(2,120)=4.06, p<.05$, $\eta^{2}=.065$; 3) personal-emotional $F(2,120)=9.00, p<.001, \eta^{2}=1.33$; and 4$)$ attachment $F(2$, 120) $=4.14, p<.05, \eta^{2}=.066$ (see Table 3). On the academic subscale, female students who reported choosing to retire $(M=49.64, S D=10.01)$ reported the highest level of adjustment, 
while females who reported being forced to retire had the lowest adjustment to college scores ( $M$ $=42.07, S D=6.84)$. The same pattern of adjustment was evidenced on the social subscale. Females who chose to retire $(M=50.60, S D=9.32)$ reported a high level of adjustment, while females who were forced to retire displayed the lowest level $(M=45.00, S D=8.07)$. Females who chose to retire also reported the highest personal-emotional adjustment subscale scores ( $M=$ 46.92, $S D=8.67)$. Females who were forced to retire had the lowest adjustment scores $(M=$ 38.49, $S D=6.11$ ). On the attachment to the university subscale, females who chose to retire had the highest level of adjustment $(M=50.97, S D=9.14)$, while males who were forced to retire had the lowest level of adjustment $(M=42.79, S D=9.40)$ on this subscale.

\section{Discussion}

The five purposes of this study were to investigate: 1 ) the possible differences in reported levels of athletic identity between disengaged high school senior athletes, high school senior non-athletes, and first-year college athletes; 2) the possible differences between the college adjustment experiences of disengaged high school senior athletes, high school senior nonathletes, and first-year college athletes; 3) how identification with athletic role might impact adjustment experiences of retired high school senior athletes; 4) how divestment from the athletic role may be related to adjustment to college for retired high school senior athletes; and 5) how past athletic experiences may predict adjustment to college for retired high school senior athletes. Overall, results suggested that retired high school senior athletes experienced college adjustment differently than their first-year peers. It was learned that the adjustment of these students might be influenced by their identification with the athletic role. However, due to the low to moderate effect sizes found in the statistical analyses with college adjustment as the dependent measure, more research may be needed to confirm these findings. 


\section{College Freshmen Level of Athletic Identity and Overall Adjustment}

Data analyses revealed that the three athletic status and gender groups significantly differed from each other in reported level of athletic identity. These results resembled other research findings on athletic identity where college and elite athletes who were still participating in competitive or high-level sport displayed a higher identification with the athletic role and those with no past experiences as athletes displayed quite low, sometimes absent, levels of athletic identity (Brewer \& Cornelius, 2001). However, in this study, the recently retired group reported athletic identity levels overlapping with those defined as current athletes and nonathletes in previous research (Brewer \& Cornelius, 2001).

Results suggest that the first semester of college may be a time of transition for some where there is simultaneously both a residual identification with the athletic role and a divestment from this self-view. Consequently, transitioning students may need to be considered an in-between sub-group of athletes who might differ in identity formation/exploration than the historical categories of "athlete" and "non-athlete" found in this line of research (Brewer et al., 1993; Grove et al., 1997; Hale, James, \& Stambulova, 1999). In addition, the RHSA group displayed a significantly different level of athletic identity than the overall norms of athletes and non-athletes from numerous past investigations (Brewer and Cornelius, 2001). This recently retired group of "transitional athletes" may need to be considered a separate group from the traditional dichotomy of "athletes" and "non-athletes." Because of their unique situation, transitional athletes might require certain adjustment-oriented services matched to their experience (i.e., career exploration, personal discovery) to aid in their divestment.

Freshmen females from the total sample reported higher levels of academic adjustment than their male counterparts. This finding was consistent with previous studies that found both 
female athlete and non-athlete samples had higher academic outcomes than males on grade point average (Burke, 1989; Miller, Melnick, Barnes, Farrell \& Sabo, 2005) and other behaviors associated with academic performance (e.g., better class attendance, taking notes, and reading the book) (Zusman, Knox \& Lieberman, 2005). However, on the three other SACQ college adjustment subscales, males and females mirrored each other in their reported levels of adjustment. This lack of significant difference between genders has been recently supported by Pascarella and Terenzini (2005) who learned that social self-concept might not vary by gender when student background and institutional characteristics are held constant.

The significant difference between genders found in academic adjustment might also be a result of the impact of recent mid-term evaluations, which were e-mailed to all students two days prior to the beginning of data collection. Feedback on their academic progress might have inspired them to more honestly assess their true academic performance, therefore supporting current research on academic performance between genders (e.g., Miller et al., 2005). The nonsignificant differences on the other subscales may be attributed to the absence of a mid-term evaluation assessing an individual's level of adjustment in non-academic areas. Therefore, an individual's self-reported level of social and personal/emotional adjustment or attachment to the university might be quite different than the actual level of adjustment.

\section{Retired High School Senior Athlete College Adjustment}

Given that retired high school senior athletes might report experiences that set them apart from both current varsity athletes and students who do not participate in sport, it is important to investigate why this may affect adjustment to the college environment. Female retired athletes reported a higher level of attachment to the university than male retired athletes. This SACQ subscale was designed to measure a student's level of commitment to both educational goals and 
the degree of attachment to the specific institution one is attending, and the quality of the bond between the student and the institution (Baker \& Siryk, 1999). This higher level of attachment may be related to theory suggesting that females tend to develop interpersonal bonds more quickly than do males (Gilligan, 1982).

In relation to athletic identity formation, females may be less likely to commit to an athletic role when solid information about career options and lifestyle choices are presented convincingly (Pascarella \& Terenzini, 2005). Consequently freshmen women may be more open to what the university offers them in the form of developing career and life goals (Chapman, 1989). In contrast, freshmen males may be more reluctant in shedding their athletic identity in light of possibly being unprepared academically (Pearson \& Petitpas, 1990). As previously mentioned, freshman year, according to Medalie (1981), is a process of divestment from past roles and investment in new, more appropriate ones. However, if a first-year male is not prepared for or confident in the roles of a college student, he may hold onto old roles (i.e., being an athlete) inappropriately as a measure of safety.

An interesting finding was that the retired athlete group with a moderate level of athletic identity displayed significantly lower SACQ academic adjustment scores than both the high and low athletic identity groups. Unlike students who strongly identified with the athletic self-view who might seek out experiences that complement their athletic identity and lack the need to completely divest (e.g., choosing a sport-related academic major), or who did not identify with an athletic identity and had no need to athletically divest (e.g., embarked on an academic or career path in high school realizing that sport was not going to be a priority), participants with a moderate level of athletic identity may be in a sort of transitional identity limbo. Athletes 
identifying moderately with the athletic role might not have had a strong identification with any viable future roles and so may be unsure of what the future may hold for them.

These results are not surprising when considering the wealth of theory investigating the transition and adjustment during freshman year (Medalie, 1981; Pearson \& Petitpas, 1990; Schlossberg, 1981). Specifically, this period of transition for students is often a time of dealing with uncertainty, establishing an identity, and clarifying one’s purpose (Chickering \& Reisser, 1969; Erikson, 1950). Therefore, like non-athlete college students, these transitional athletes (i.e., RHSAs) likely do not have aspirations of a professional career in sport and services such as career exploration and may become highly beneficial during the freshman year. Role of Social Support and Choice in Retirement on College Adjustment

When investigating the influence of athletic identity on life transition and student adjustment to college, there are three factors that seem to relate to positive adjustment outcomes: 1) social support (Pearson \& Petitpas, 1990), 2) positive self-identity (McPherson, 1980), and 3) choice in the retirement process (Taylor \& Ogilvie, 2001). In this study, there were two demographic variables that influenced college adjustment for retired high school senior athletes during their freshman year of college: 1) perceived social support, and the 2) the nature of their decision to retire.

Female retired athletes with a high level of perceived social support were found to have adjusted better socially and felt more attached to their university. For females, relationships are historically viewed as an important part of one's worldview and are linked to one’s own identity (Chapman, 1989). Also, peer group support is seen as an important part of female adjustment. Without a high level of social support, females may have a higher potential for adjustment difficulties in new situations (Gilligan, 1982). 
In this study, retired athletes who reported making the personal decision to retire adjusted better during their first semester than those who were forced to retire. On the SACQ academic, personal-emotional, and attachment subscales, females who chose to retire produced the highest adjustment scores. Similarly, females who were forced to retire from sport displayed the lowest adjustment scores on the academic, personal-emotional, and attachment subscales. When examining attachment to the university, male athletes who were forced to retire had the lowest adjustment, while both males and females who chose to retire had higher adjustment scores than those who were forced to retire. This finding may suggest that females have an easier time adjusting to college when choosing to retire and could be related to the importance of long-term supportive relationships (Chapman, 1989). Females who have control over the termination of their athletic career may make plans to remain in contact with former teammates and/or see coaches as friends (versus holding them responsible for deselection) after participation stops. Therefore, these disengaged female athletes may enter college with more of their past supportive relationships intact. Females who were forced to retire may not have had the ability to maintain past supportive athletic relationships nor had positive associations with past teammates or coaches, negatively influencing their adjustment.

Athletes who chose to disengage from sport may have had more of an inclination relating to their future retirement from athletics once high school participation ended (Taylor \& Ogilvie, 2001). However, athletes who were forced to retire and had no choice might still have retained their self-view as athlete in hopes of perhaps continuing in their participation in the future (i.e., possessing a high level of athletic identity). As a result, identity foreclosure may have occurred during the high school sport participation years for these athletes, where the athletic role was 
embraced as highly viable, to the detriment of other more appropriate roles (Marcia, Waterman, Matteson, Archer, \& Orlofsky, 1993).

Participants who chose to retire had higher adjustment scores than athletes who were forced to retire. The impact of personal choice in retirement and the differences between the athletes who chose to retire and those who were forced to retire may be corollary to an athlete's perception of his or her locus of control (McKelvie \& Huband, 1980). Athletes have been found to possess a greater internal locus of control due to participation in competitive situations (Morris, Vaccaro, \& Clarke, 1979) and internal athletes may be less anxious than external athletes (Rotter, 1975). Therefore, athletes with a high internal locus of control may have difficulty adjusting to retirement when it is out of their hands. This combination of holding on to a pre-established athletic identity, lack of identity exploration, and possessing an internal locus of control may be linked to poor college adjustment (Murphy et al., 1996), as well as retarding the divestment/investment process that is critical in college adjustment during the freshman year (Medalie, 1981).

\section{Limitations}

There were several threats to both internal and external validity that might have influenced the results of this study. First, the sample used in this study was one of convenience and did not include a true random sample of university students. Second, this study employed only a single dependent measure of adjustment to college (i.e., SACQ) during the ninth and tenth weeks of the fall semester. This single measure approach only provided a snapshot of the first semester adjustment experiences of college freshman sampled. While it provided a basis of analysis for the adjustment experience, repeated measures of adjustment could provide a more in-depth look at true semester-long adjustment to college. Third, the Hawthorne effect (i.e., 
individual behaviors could have been altered because participants knew they were being evaluated) and demand characteristics (i.e., participants may infer the rationale of the study and possibly attempt to confirm the experimenter's hypothesis) need to be considered when assessing the relevance of this study. Fourth, only $71 \%$ of the RHSA/NA participants accurately completed the assessment packet or were of traditional college age (i.e., 17-19 years-old), and were included in the study. Finally, the procedures of this study were altered just prior to data collection. The initial data collection consisted of only UASC workshop and student-athlete orientation class participants, however, due to concerns relating to the statistical power of the analyses, the decision was made to collect data from two general orientation classes as well.

There are other limitations of this study that affect its generalizability to the real-world population of transitioning freshman retired high school athletes adjusting to the college environment. First, this study proposed that senior high school athletes were highly invested in the athletic role and that athletic participation was an integral part of their lives. Therefore, it used year-by-year participation to define the retired athlete group, not a self-reported level of involvement/dedication to athletics. In light of this, there could be a number of senior athletes whose participation in sport was just part of the high school experience and not one of necessity to an individual's identity. Second, the adjustment experiences of the participants in this study were assessed late in their first semester (i.e., after the mid-term). The timing of the assessment could have excluded some students that already dropped out or left school because of their limited or non-existent adjustment to the college environment. The first semester students who did not persist to week nine of the first semester could have provided different results for the study and affected the adjustment scores between the adjustment groups used in this study. Lastly, participants recruited for this study were found in both advising workshops and 
orientation classes. The fact that they had signed up for a workshop and attended either the workshop or the class period in which they were assessed, infers a certain level of adjustment (i.e., importance of major planning and/or the value of attendance). If students were absent from either the workshop or the orientation class, this could be a sign of maladjustment that was not measured due to their absence from the study.

\section{Future Directions}

This study provides several potential future directions for study in the area of retired high school athlete adjustment to college, specifically the impact of athletic identity and athletic disengagement on college adjustment. It seems that one of the most influential aspects of a retired athlete's future as a non-athlete is one's perceived control over the decision to retire. Whether an athlete feels that it was his or her choice to retire, versus being forced out of this role by powerful others, can shape a disengaged athlete's adjustment to new roles and experiences outside of athletics. This aspect of the retirement process would seem to be a valuable area of study, resulting in a greater ability to aid transitioning/retiring athletes. Complementing this exploration of choice, it seems that adding an intervention for retired athletes could have a positive effect on retired athletes adjusting to the university setting. Currently, most students are required to take some type of orientation course that aids in adjustment to college for all types of students. If an orientation course could be designed especially for retired high school athletes aimed at aiding in the transition from athlete to non-athlete, with an emphasis on retirement and personal choice, this may increase the adjustment and retention of this population. With this unique course offering, researchers could investigate the application of this study's findings by having retired athletes engage in guided personal exploration compared to a general freshmanlevel orientation course. 
The individual level of divestment for retired high school senior athletes has the potential to mediate adjustment difficulties in the instance of retiring from athletics and finding new, more appropriate roles (Allison \& Meyer, 1988; Curtis \& Ennis, 1988). In the current study, both the current level and a retrospective level of athletic identity were measured. To measure divestment, the current level of athletic identity was subtracted from the retrospective level to establish a divestment score. While the intentions of this measure of "divestment" were noble, it seems that this measure left something to be desired. Instead of having participants reflect back upon their perceived level of athletic identity from a year past, it may be more effective to have access to these participants during their senior year in high school, where athletic identity could be measured at that present time. Having this “current” level of athletic identity in high school, then measuring it again during the first semester of college, would provide a more sound measure of true divestment during the transition between a participant's senior year in high school and the first semester in college.

It seems important to further investigate how personal choice in retirement may affect the college adjustment experiences of retired high school athletes. By gaining insight into this specific population's experience in adjusting to college (i.e., how the decision to retire from sport and the impact of locus of control may affect subsequent college adjustment), overall retention of first-year students may be increased. These findings also highlight the importance of the role of personal choice in high school sport retirement for disengaged female athletes. According to Evans, Forney, and Guido-DiBrito (1998), there is a paucity of research concerning college adjustment experiences of females. A study pertaining specifically to female retired athletes and the role of personal choice on their adjustment could shed light on the impact of locus of control as well as adding to the overall body of research in the area. 
Finally, to further research in the area of athletic identity/participation and adjustment to college, it would seem appropriate to develop a college adjustment measure that is specific to an athletic population. While the SACQ seems to be the most used reliable and valid measure of college student adjustment in recent literature, it does not specifically take into account one’s past experiences of being an athlete. While this may not be considered a downfall of this measure when assessing general student adjustment, it might be of concern when relating its findings to populations with an athletic background (e.g., retired high school athletes, current college athletes). Therefore, the development of a reliable and valid measure that can be used with an athletic population seems warranted to further the knowledge in this area. While the development of a reliable and valid measure can be quite an undertaking, with athletics becoming more of a central focus in our society (Eitzen \& Sage, 2003), it seems appropriate to aid in the future study of this phenomenon. 


\section{References}

Allison, M.T., \& Meyer, C. (1988). Career problems and retirement among elite athletes:

The female tennis player. Sociology of Sport Journal, 5, 212-222.

Anderson, D.F., \& Cychosz, C.M. (1994). Development of an exercise identity scale. Perceptual Motor Skills, 78, 747-751.

Baker, R.W., \& Siryk, B. (1984). Measuring adjustment to college. Journal of Counseling Psychology, 31, 179-189.

Baker, R.W., \& Siryk, M.A. (1999). Student Adaptation to College Questionnaire manual. Los Angles, CA: Western Psychological Services.

Ballie, P.H.F., \& Danish, S.J. (1992). Understanding the career transition of athletes. The Sport Psychologist, 6, 77-98.

Blinde, E.M., \& Greendorfer, S.L. (1985). A reconceptualization of the process of leaving the role of competitive athlete. International Review for the Sociology of Sport, 20(1-2), 87-94.

Blinde, E.M., \& Stratta, T.M. (1992). The “sport career death” of college athletes: Involuntary and unanticipated sport exits. Journal of Sport Behavior, 15, 3-20.

Brewer, B. W., \& Cornelius, A. E. (2001). Norms and factorial invariance of the Athletic Identity Measurement Scale. Academic Athletic Journal, 16,103-113.

Brewer, B.W., Van Raalte, J., \& Linder, D.E. (1993). Athletic identity: Hercules’ muscles or Achilles’ heel? International Journal of Sport Psychology, 24, 237-254.

Burke, P.J. (1989). Gender identity, sex, and school performance. Social Psychology Quarterly, 52, 159-169.

Chan C.S., \& Grossman, H.Y. (1988). Psychological effects of running loss on 
consistent runners. Perceptual and Motor Skills, 66, 875-883.

Chickering, A. W. (1999). Personal qualities and human development in higher education: Assessment in the service of educational goals. In S.J. Messick (Ed.), Assessment in higher education: Issues of access, quality, student development, and public policy (pp. 13-33). New Jersey: Lawrence Erlbaum Associates.

Chickering, A. W. (1981). The modern American college. San Francisco: Jossey-Bass.

Chickering, A. W., \& Reisser, L. (1969). Education and identity (2nd ed.). San Francisco: Jossey-Bass.

Coakley, J.J. (1983). Leaving competitive sport: Retirement or rebirth? Quest, 35, 1-11.

Curtis, J., \& Ennis, R. (1988). Negative consequences of leaving competitive sport? Comparative findings for former elite-level hockey players. Sociology of Sport Journal, 5, 87-106.

Danish, S.J. (1981). Life-span human development and intervention: A necessary link. Counseling Psychologist, 9, 40-43.

Danish, S.J., Owens, S.S., Green, S.L., \& Brunelle, J.P. (1997). Building bridges for disengagement: The transition process for individuals and teams. Journal of Applied Sport Psychology, 9, 154-167).

Dunkel-Schetter, C., \& Lobel, M. (1990). Stress among students. New Directions for Student Services, 19, 17-34.

Eitzen, S.D., \& Sage, G.W. (2003). Sociology of North American sport (7th ed.). Dubuque, IA: William C. Brown/McGraw-Hill.

Erikson, E. (1950). Childhood and society. New York: Norton.

Evans, N.J., Forney, D.S., \& Guido-DiBrito, F. (1998). Student development in college: 
theory, research, and practice. San Francisco, CA: Jossey-Bass.

Farnsworth, D. (1966). Psychiatry, education, and the young adult. Springfield, IL:

Charles C. Thomas.

Gilligan, C. (1982). In a different voice: Psychological theory and women's development. Cambridge, MA: Harvard University Press.

Greendorfer, S.L., \& Blinde, E.M. (1985). Retirement from intercollegiate sport: Theoretical and empirical considerations. Sociology of Sport Journal, 2, 101-110.

Grove, J.R., Lavallee, D., \& Gordon, S. (1997). Coping with retirement from sport: The influence of athletic identity. Journal of Applied Sport Psychology, 9, 191-203.

Hale, B.D., James, B., \& Stambulova, N. (1999). Determining the dimensionality of athletic identity: A Herculean cross-cultural undertaking. International Journal of Sport Psychology, 30, 83-100.

Havighurst, R.J. (1952). Developmental tasks and education. New York: Longmans Green.

Hildebrand, K.M., Johnson, D.J., \& Bogle, K. (2001). Comparison of patterns of alcohol use between high school and college athletes and non-athletes. College Student Journal, 35, 358-366.

Leddy, M.H., Lambert, M.J., \& Ogles, B.M. (1994). Psychological consequences of athletic injury among high-level competitors. Research Quarterly for Exercise and Sport, 65(4), 347-354.

Marcia, J.E., Waterman, A.S., Matteson, D.R., Archer, S.L., \& Orlofsky, J.L. (1993). Ego identity: A handbook for psychological research. New York: Springer-Verlag.

Martin Jr., W.E., Swartz-Kulstad, J.L., \& Madison, M. (1999). Psychological factors that 
predict the college adjustment of first-year undergraduate students: Implications for college counselors. Journal of College Counseling, 2(2), 121-134.

McKelvie, S.J. \& Huband, D.E. (1980). Locus of control and anxiety in college athletes and non-athletes. Perceptual and Motor Skills, 50, 819-822.

McPherson, B.D. (1980). Retirement from professional sport: The process and problems of occupational and psychological adjustment. Sociological Symposium, 30, 126-143.

Medalie, J. (1981). The college years as a mini-life cycle: developmental tasks and adaptive options. College Health, 30, 75- 79.

Mihovilovic, M. (1968). The status of former sportsman. International Review of Sport Sociology, 3, 73-96.

Miller, K.E., Melnick, M.J., Barnes, G.M., Farrell, M.P., \& Sabo, D. (2005). Untangling the links among athletic involvement, gender, race, and adolescent academic outcomes. Sociology of Sport Journal, 22, 178-193.

Morris, A.F., Vaccaro, P., \& Clarke, D.H. (1979). Psychological characteristics of agegroup competitive swimmers. Perceptual and Motor Skills, 48, 1265-1266.

Morris, D. (1997). The role of transitions in loneliness and homesickness: The case of the transition to college. Dissertation Abstracts International Section A: Humanities \& Social Sciences, 57(10-A), 4262.

Murphy, G.M., Petitpas, A.J., \& Brewer, B.W. (1996). Identity foreclosure, athletic identity, and career maturity in intercollegiate athletes. The Sport Psychologist, 10, 239246.

National Collegiate Athletic Association (NCAA) (n.d.). Estimated probability of 
competing in athletics beyond the high school interscholastic level. Retrieved March 21, 2006, from http://www.ncaa.org/

Neugarten, B.L. (1979). Time, age, and the life cycle. American Journal of Psychiatry, 136(7), 887-894.

Ogilvie, B.C., \& Howe, M. (1986). The trauma of termination from athletics. In J.M. Williams (Ed.), Applied sport psychology: Personal growth to peak performance (pp. 365-382). Palo Alto: Mayfield Publishing.

Oppenheimer, B.T. (1984). Short-term small group intervention for college freshmen. Journal of Counseling Psychology, 31(1), 45-53.

Pascarella, E.T., \& Terenzini, P.T. (2005). How college affects students (vol. 2). San Francisco: Jossey-Bass.

Paul, E.L., \& Brier, S. (2001). Friend sickness in the transition to college: Precollege predictors and college adjustment correlates. Journal of Counseling \& Development, 79(1), 77-89.

Person, R.E., \& Petitpas, A.J. (1990). Transitions of athletes: Developmental and preventive perspectives. Journal of Counseling and Development, 69, 7-10.

Rotter, J.B. (1975). Some problems and misconceptions related to the construct of internal versus external control of reinforcement. Journal of Consulting and Clinical Psychology, 43, 56-67.

Schlossberg, N.K. (1981). A model for analyzing human adaptation to transition. Counseling Psychologist, 9, 2-18.

Sher, K.J., Wood, P.K., \& Gotham, H.J. (1996). The course of psychological distress in 
college: A prospective high-risk study. Journal of College Student Development, 37(1), $42-51$.

Sinclair, D.A., \& Orlick, T. (1993). The effects of transition on high-performance sport. In D. Hackfort (Ed.), Psychosocial issues and interventions in elite sports (pp. 29-55). Frankfurt: Lang.

Sparkes, A.C. (1998). Athletic identity: An Achilles' heel to the survival of self. Qualitative Health Research, 8(5), 644-664.

Swain, D.A. (1991). Withdrawal from sports and Schlossberg's model of transitions. Sociology of Sport Journal, 8, 152-160.

Taylor, J., \& Ogilvie, B.C. (2001). Career transition among athletes: Is there life after sports? In J.M. Williams (Ed.), Applied sport psychology: Personal growth to peak performance ( $4^{\text {th }}$ ed., pp. 365-382). Palo Alto: Mayfield Publishing.

Vickio, C.J. (1990). The goodbye brochure: Helping students to cope with transition and loss. Journal of Counseling \& Development, 68(5), 575-577.

Webb, W.M., Nasco, S.A., Riley, S., \& Headrick, B. (1998). Athlete identity and reactions to retirement from sports. Journal of Sport Behavior, 21(3), 338-362.

Werthner, P., \& Orlick, T. (1986). Retirement experiences of successful Olympic athletes. International Journal of Sport Psychology, 17, 337-363.

Zusman, M., Knox, D., \& Lieberman, M. (2005). Gender differences in reactions to college requirements or "why females are better students." College Student Journal, 39(4), 621-626. 
Table 1

Retired Athletes' Level of Identity and Adjustment to College

Subscales of SACQ

\begin{tabular}{lcccc}
\hline & Academic & Social & Per-Emo* & Attachment \\
Males $(M, S D)$ & $44.06,9.38$ & $48.75,8.40$ & $42.94,9.28$ & $45.62,9.59$ \\
High Identity & $45.67,6.84$ & $49.00,10.78$ & $43.52,10.54$ & $46.81,12.00$ \\
Moderate Identity & $39.73,8.21$ & $47.64,6.35$ & $39.55,5.24$ & $43.23,7.85$ \\
Low Identity & $47.10,11.36$ & $49.70,7.81$ & $46.05,10.47$ & $47.00,8.37$ \\
\hline Females $(M, S D)$ & $46.77,9.38$ & $48.69,9.14$ & $43.77,8.73$ & $49.07,9.17$ \\
High Identity & $48.10,9.49$ & $51.19,9.54$ & $43.52,10.00$ & $51.48,8.42$ \\
Moderate Identity & $45.33,10.13$ & $47.42,9.63$ & $42.71,7.46$ & $47.92,10.71$ \\
\hline Low Identity & $47.04,8.70$ & $47.80,8.21$ & $45.00,8.92$ & $48.16,8.10$ \\
\hline
\end{tabular}

* Personal-Emotional subscale of the SACQ 
Table 2

Correlation Matrix of Divestment and SACQ Subscales by Gender for RHSAs

Males

Divestment Academic Social Per-Emo** Attachment

Divestment $\quad 1.00$

$\begin{array}{lll}\text { Academic } & .157 & 1.00\end{array}$

$\begin{array}{llll}\text { Social } & .192 & .603^{*} & 1.00\end{array}$

$\begin{array}{lllll}\text { Per/Emo } & .080 & .674^{*} & .689 * & 1.00\end{array}$

$\begin{array}{llllll}\text { Attachment } & .65 & .635^{*} & .902 * & .673^{*} & 1.00\end{array}$

Females

Divestment Academic Social Per/Emo Attachment

Divestment $\quad 1.00$

$\begin{array}{lll}\text { Academic } & -.033 & 1.00\end{array}$

$\begin{array}{lll}\text { Social } & .039 & .419 *\end{array}$

$\begin{array}{lllll}\text { Per/Emo } & -.096 & .625^{*} & .486^{*} & 1.00\end{array}$

$\begin{array}{llllll}\text { Attachment } & .037 & .417 * & .909 * & .419 * & 1.00\end{array}$

${ }^{*} p<.01$

** Personal-Emotional subscale of the SACQ 
Table 3

Retired Athletes Decision to Retire and Adjustment to College

Subscale of SACQ

\begin{tabular}{|c|c|c|c|c|}
\hline & Academic & Social & Per-Emo* & Attachment \\
\hline Males & $44.51,9.45$ & $48.20,8.41$ & 43.29, 9.52 & $44.89,9.29$ \\
\hline Chose to Retire & $44.79,11.11$ & $49.42,8.44$ & $44.87,9.65$ & $46.52,9.02$ \\
\hline Forced to Retire & $44.29,6.96$ & $46.63,8.29$ & $41.25,9.15$ & $42.79,9.40$ \\
\hline Females & $46.55,9.56$ & 48.30, 9.19 & $43.47,8.74$ & $48.73,9.16$ \\
\hline Chose to Retire & $49.64,10.01$ & $50.59,9.32$ & $44.87,9.65$ & $50.97,9.14$ \\
\hline Forced to Retire & $42.07,6.39$ & $45.00,8.07$ & $38.48,6.11$ & $45.48,8.32$ \\
\hline
\end{tabular}

* Personal-Emotional subscale of the SACQ 
College Adjustment 35

\section{APPENDIX A}

Demographic Questionnaire 


\section{Demographics}

DIRECTIONS: Please complete the following questions to the best of your knowledge. Please circle or fill in only one answer for each question unless otherwise specified.

1) Gender: Male Female

2) Race: Asian African-American Latino Caucasian Other

3) Age (in years): Under $18 \quad 18-19 \quad 20-21 \quad 22-23 \quad 24-25 \quad 26$ \& Over

4) Class Standing: Freshman Sophomore Junior Senior

5) Is this your first semester of college at any university? $\quad$ YES NO

6) Did you transfer to WVU from another school? $\quad$ YES NO

7) What is your planned major at this time?

8) Are you a current WVU varsity athlete? $\quad$ YES NO

9) If you answered "YES” to question \#8, what sport(s) do you play at WVU?

10) Do you plan on pledging a fraternity or sorority $\quad$ YES NO this fall or spring?

11) How many days per week (on average) do you use the Student Recreation Center?

12) Do you currently participate in an intramural sports league $\quad$ YES NO at the WVU Student Recreation Center?

13) How much support do you feel you have from family and friends while you are here at WVU?

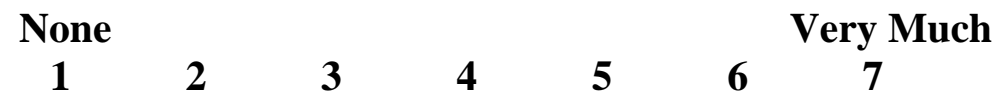
14) Did you play a varsity sport in high school?
YES NO 


\section{IMPORTANT!}

If you answered "YES" to question \#14 (you played a varsity sport in high school) please CONTINUE and answer the remaining questions.

If you answered "NO" to question \#14 please STOP here. You have completed this section of the survey. Skip over the next page and continue at the next section (Section \#2).

15) What varsity sport(s) did you play in high school?

(Please list your primary varsity sport first):

16) What year(s) did you play your primary varsity sport in high school?

(Circle all that apply): Freshman Sophomore Junior Senior

$\begin{array}{lll}17) & \text { Were you a starter for your high school team } & \text { YES }\end{array}$ playing your primary varsity sport?

18) If you answered "YES" to question \#17, what years were you a starter?

(Circle all that apply): Freshman Sophomore Junior Senior

19) At any point during your 4 years in high school, $\quad$ YES NO did you expect to play your varsity sport in college?

20) If you answered "YES" to question \# 19, what year(s) in high school did you have the expectation to play varsity sports in college?

(Circle all that apply): Freshman Sophomore Junior Senior

21) Were you recruited by a coach to play your primary $\quad$ YES NO

high school varsity sport at the college level?

22) Were you offered an athletic scholarship by a coach to play $\quad$ YES NO your primary high school varsity sport at the college level?

23) Circle the ONE statement among the following three statements that best describes you:

A.) I chose to retire from my high school varsity sport.

B.) I did not want to retire, but someone/something forced me to retire from my high school varsity sport.

C.) I am still competing in my high school varsity sport on a regular basis, therefore I would not consider myself retired. 
24) If you answered choices " $A$ " or " $B$ " to question \# 23, what is the primary reason why you are not playing college sports presently? (Circle ONLY ONE of the following choices):

Need to prioritize my time around my academics

Need to work while in school

Lost interest

I did not have the skill / ability to play my sport at the collegiate level

Was not recruited by college coaches

Lost motivation

Sustained career-ending injury

My sport was not offered as a varsity sport at this university

Other: 


\section{APPENDIX B}

Athletic Identity Measurement Scale (AIMS) 


\section{DIRECTIONS}

Please circle the number that best reflects the extent to which you agree or disagree with each statement regarding your sport participation AT THIS MOMENT.

\section{Strongly \\ disagree}

\section{Strongly \\ agree}

\begin{tabular}{|c|c|c|c|c|c|c|}
\hline I consider myself an athlete. & 1 & 2 & 3 & 4 & 5 & 6 \\
\hline I have many goals related to sport. & 1 & 2 & 3 & 4 & 5 & 6 \\
\hline Most of my friends are athletes. & 1 & 2 & 3 & 4 & 5 & 6 \\
\hline Sport is the most important part of my life. & & 2 & 3 & 4 & 5 & 6 \\
\hline $\begin{array}{l}\text { I spend more time thinking about sport } \\
\text { than anything else. }\end{array}$ & 1 & 2 & 3 & 4 & 5 & 6 \\
\hline $\begin{array}{l}\text { I feel bad about myself when I do poorly } \\
\text { in sport. }\end{array}$ & 1 & 2 & 3 & 4 & 5 & 6 \\
\hline $\begin{array}{l}\text { I would be very depressed if I were injured } \\
\text { and could not compete in sport. }\end{array}$ & & 2 & 3 & 4 & 5 & 6 \\
\hline
\end{tabular}


College Adjustment 41

\section{APPENDIX C}

Retrospective Athletic Identity Measurement Scale (R-AIMS) 


\section{DIRECTIONS}

Please circle the number that best reflects the extent to which you agree or disagree with each statement regarding your sport participation ON THIS DAY, ONE YEAR AGO.

\section{Strongly \\ disagree}

\section{Strongly \\ agree}

\begin{tabular}{|c|c|c|c|c|c|c|}
\hline I considered myself an athlete. & 1 & 2 & 3 & 4 & 5 & 6 \\
\hline I had many goals related to sport. & 1 & 2 & 3 & 4 & 5 & 6 \\
\hline Most of my friends were athletes. & 1 & 2 & 3 & 4 & 5 & 6 \\
\hline $\begin{array}{l}\text { Sport was the most important part of my } \\
\text { life. }\end{array}$ & 1 & 2 & 3 & 4 & 5 & 6 \\
\hline $\begin{array}{l}\text { I spent more time thinking about sport } \\
\text { than anything else. }\end{array}$ & 1 & 2 & 3 & 4 & 5 & 6 \\
\hline $\begin{array}{l}\text { I felt bad about myself when I did poorly } \\
\text { in sport. }\end{array}$ & 1 & 2 & 3 & 4 & 5 & 6 \\
\hline $\begin{array}{l}\text { I would have been very depressed if I were } \\
\text { injured and could not compete in sport. }\end{array}$ & & 2 & 3 & 4 & 5 & 6 \\
\hline
\end{tabular}


College Adjustment 43

APPENDIX D

Review of Literature 


\section{REVIEW OF LITERATURE}

\section{Introduction}

The end product of all athletic careers is disengagement. No matter if an athlete is elite, amateur, or high school at some point in time, organized participation must end. Sport psychology literature suggests that this can elicit emotional and psychological disturbance (Mihovilovic, 1968; Sinclair \& Orlick, 1993; Weiss \& Troxel, 1986; Werthner \& Orlick, 1986); positive feelings such as relief, happiness, and satisfaction (Allison \& Meyer, 1988; Blinde \& Greendorfer, 1985; Curtis \& Ennis, 1988); or be seen as a normal, expected transition (Coakley, 1983). Much of how a disengaging athlete interprets retirement appears to depend on factors such as the level of identification with the athletic role, support systems, planning for disengagement, and coping strategies (Pearson \& Petitpas, 1990; Taylor \& Ogilvie, 2001).

One specific population of athletes that has not been investigated by disengagement researchers is high school athletes. Research is apparently lacking in this area for two reasons. First, high school athletes are at a stage in life in which psychological theory postulates that many roles and identities are open to them and because of this, a strong commitment to one role (in this case athletics) is not warranted and losing this role will not sufficiently impact functioning (Erikson, 1950). Second, disengagement from high school sport and moving on to college as a non-athlete can be seen as a normal, expected transition that the retiring athlete has time to prepare and plan for (Coakley, 1983; Murphy, Petitpas \& Brewer, 1996).

Being an athlete in high school is still one of the most viable ways to achieve high social status during adolescence (Coleman, 1959; Eitzen, 1975; Marsh, 1993). The face of high school sport is changing where more and more individuals are participating in sport. In 2003, over 2.3 million high school students participated in major sports (NCAA, 2004). As a society, we place 
an increasingly higher value on those that are good in sport. To achieve this higher social standing, athletes must invest more time, energy, and focus on sport. This increased investment may result in an increased identification in the athletic role, thus increasing the probability that when the "expected" disengagement out of sport and subsequent transition to college occurs, the emotional and psychological disturbances normally reserved for elite and professional athletes may occur for high school athletes as well.

\section{Sport Disengagement}

\section{Theories of Disengagement}

When disengagement from sport first became a popular topic in the literature early in the 1970s, two psychological theories were used to explain the process. These two theories, social gerontology and thanatology, were used as the basis for much of the early research (Blinde \& Greendorfer, 1985).

Social gerontology postulates that life satisfaction becomes important when looking at adjustment to a new life after retirement (Rosenberg, 1981). The critical variable in this analysis is aging and how it affects an individual's adaptation to new roles. This concept has been used to explain global life satisfaction after a full occupational career. Blinde and Greendorfer (1985) question this theory's application to athletes for two significant reasons. First, disengaging athletes are more likely to be quite younger (possibly over 20 years younger) than those retiring from the work force, and therefore, cannot afford to withdraw from society as the theory implies. Second, while those who have completed a full career might experience adjustment problems, this might not be applicable to retired athletes who have to face the social and economic realities of a second career. 
Thanatology is the study of death and dying and is linked to situations (e.g., retirement from sport) in which an individual is socially dead while the body is still alive (Lerch, 1984). More specifically, this social death is attributed to the social isolation felt resulting from retirement. In the sporting context, this idea is applied to the disengaging athlete's experience of “sport career death” (Blinde \& Greendorfer, 1985; Blinde \& Stratta, 1992). Blinde and Greendorfer believe that thanatology has been applied to sport through qualitative interviews conducted with former athletes who have experienced adjustment difficulties, which included social isolation following disengagement. The problem with relying on thanatology is its overidentification with the negative side of sport retirement experience as if the social death of an athlete is generalizable to the experiences of a majority of retired athletes.

Erikson's (1950) stage theory of psychosocial development, found in the developmental psychology literature, has also been applied to sport disengagement in recent years (Lavallee \& Andersen, 2000). Three of Erikson's stages are of particular interest, mirroring the age of the transitioning athlete, these being: 1) identity (late adolescence), 2) intimacy (early 20s), and 3) generativity (middle adulthood). In each of these stages, the athlete must either master the developmental tasks of the stage or grow as a person, or leave tasks unresolved and stagnate as a person (Erikson, 1950). An athlete can be hindered developmentally because the tasks that have to be mastered (e.g., establishing an identity, forming intimate relationships, giving back) may have been set aside to continue to be competitive in high-level sport.

Schlossberg's (1981) theory of adaptation to transition was adapted for sport by Pearson and Petitpas (1990) to create a model for student-athlete disengagement. They believe that the disengagement process will be more difficult for those athletes who 1) have more exclusively based their identity on athletic performance; 2) have the greatest disparity between level of 
aspiration and level of ability; 3) have little experience with similar transitions; 4) are limited in their ability to adapt as a result of behavior or emotional deficits; 5) are limited in their ability to form lasting and supportive relationships; and 6) must deal with the transition without helpful emotional or material resources (Pearson \& Petitpas, 1990). These authors support identifying athletes who are "at-risk" for dysfunctional adaptation to transition. Moreover, these at-risk athletes would ideally be enrolled in preventative programs that help them acquire resources that can aid in a positive transition such as knowledge, attitudes, and skills (Petitpas, Champagne, Chartrand, Danish, \& Murphy, 1997).

\section{Mediators of the Disengagement Experience}

Some of the potential mediators of the disengagement process include coping strategies, athletic identity, pre-retirement planning, and social support (Person \& Petitpas, 1990; Taylor \& Ogilvie, 2001). For elite athletes, coping strategies such as finding other interests, keeping busy, and exercising were found to be helping in dealing with disengagement while drinking alcohol/drugs, seeking counseling, and ignoring difficulties were not found to be helpful (Sinclair \& Orlick, 1993). Athletic identity, described as how strongly an individual identifies with the role as an athlete, has been found to be negatively correlated with positive adjustment experiences in the literature (Brewer, Van Raalte, \& Linder, 1993; Grove et al., 1997; Sparkes, 1998). More specifically, it has been observed that athletes who have a strong, sports-based identity have had more difficulties adjusting to the role as a non-athlete than those with a weak, more well-rounded identity (Brewer \& Cornelius, 2001). Pre-retirement planning, described as how well an athlete prepares for life after an athletic career is completed, can positively affect the life satisfaction of a retired athlete (Perna, Ahlgren, \& Zaichkowsky, 1999). Pre-retirement planning can take the form of a variety of activities such as continuing education, occupational/ 
investment endeavors, and social networking (Taylor \& Ogilvie, 2001). Social support can be defined as social interactions intended to induce positive outcomes. Athletes who received high levels of help adjusting to life change from family and friends reported easier transitions out of sport (Bianco \& Eklund, 2001; Sinclair \& Orlick, 1993; Werthner \& Orlick, 1986). These findings were supported by Green and Weinberg (2001) who found that an athlete's level of satisfaction with his/her social support network was negatively correlated with emotional disturbance. Overall, social support has been cited in the literature as an important factor in a positive career transition (Grove, Lavallee, \& Gordon, 1997; Swain, 1991; Werthner \& Orlick, 1986).

\section{Negative Disengagement Experiences}

In one of the first published studies focusing on disengagement from high-level athletics, disengagement was portrayed as a disheartening transition that resulted in negative emotional and psychological adjustment (Mihovilovic, 1968). In this study, the maladjustments to retirement of 44 elite European soccer players were reported as clinging to teammates, escape behaviors such as alcohol and drug use, and indifference to events surrounding the retired individual. Although, in a re-examination of the data by Coakley (1983), it was found that some of the adjustment difficulties reported by the participants were not as pervasive as Mihovilovic first reported. This study was important for disengagement research for two reasons. First, it paved the way for many other important studies that helped our field understand and develop effective interventions to aid this population. Second, because of the strong, negative picture painted by the athletes interviewed in this study (e.g., alcohol abuse, anger, anxiety, depression), sport disengagement became viewed as a negative experience. Until recently, this negative view of disengagement has pervaded the theory and intervention practices of our field. 
More recent research has supported Mihovilovic’s work, showing that disengagement can have a negative impact on functioning, eliciting negative experiences and emotions such as alcohol abuse, anger, anxiety, depression, as well as other emotional problems that can haunt the elite and college athlete (Sinclair \& Orlick, 1993). A study investigating the disengagement experiences of high-level Canadian amateur athletes found many of the same results as Mihovilovic did almost 20 years earlier (Werthner and Orlick, 1986). A majority of these athletes reported having some level (extreme to moderate) of difficulty adjusting to the role as a non-athlete. More specifically, in the time period immediately after leaving sport, these athletes self-reported their lowest scores on life satisfaction, sense of personal control, and selfconfidence. As expected, with time these feelings became more positive as adjustment to the new role continued (Werthner \& Orlick, 1986).

This study comments on an important factor when investigating disengagement: even though there is difficulty adjusting to the new role of non-athlete, in almost all cases, this adjustment does happen. This factor is one of the most debated topics in the literature when gauging the positive/negative impact of disengagement. Most of the research investigating the negative response to disengagement from sport involves an athlete's unanticipated or involuntary exit from sport (Bianco \& Eklund, 2001; Blinde \& Stratta, 1992; Weiss \& Troxel, 1986). One area of focus in this line of research deals with being cut from a team due to athletic ability, also know as the inability to make it to the next level. One study found that for those athletes that could not compete at the next level, decreased life satisfaction, self-esteem, and personal control were experienced (Webb, Nasco, Riley, \& Headrick, 1998). In a qualitative study conducted with college athletes, it was found that athletes who had been cut from the team experienced a psychological reaction mirroring a death experience (Blinde \& Stratta, 1992). Although this area 
of unexpected exit from sport literature is ripe with information that describes the negative impact that disengagement can have on functioning, it has not been as integral to our understanding of the subject as the injury research conducted.

Injury has been a focal point for disengagement researchers because serious or careerending injury is truly unexpected and most athletes lack a contingency plan for dealing with its repercussions. Weiss and Troxel (1986) make us aware of the common pitfalls that an injured athlete must be made aware of if recovery and return to athletics will occur. Issues such as the injury as a stressor, interpersonal factors, and coping skills that the athlete possesses all play a part in how the injured athlete deals with and recovers from an injury. In interviews with 10 elite and college athletes, the most common responses to injury were fear, tension, disbelief, depression, and somatic complaints (Weiss \& Troxel, 1986). The self-perceptions of injured athletes are also an important factor to consider when looking at the negative impact that injury can have on an athlete. Chan and Grossman (1988) found that seriously injured runners experienced more depressive symptoms, anxiety, confusion, and reduced self-esteem than runners who were not injured. Leddy, Lambert, and Ogles (1994) used a large sample of college athletes to assess the emotional response to real-life serious injury. It was found that within one week of experiencing the injury and at a two-month follow-up, high-level athletes are susceptible to emotional responses following injury such as increased depression and anxiety and decreased self-esteem as compared to non-injured athletes. Moreover, some of the reported levels of these emotions by injured athletes were similar in intensity to non-athletic clients receiving outpatient psychotherapy (Leddy, Lambert, \& Ogles, 1994). As reported in the Webb et al. study (1998), injured athletes experienced the most difficult adjustment to retirement of all the groups, even more than the athletes who were "cut" from the team. In an in-depth narrative, a single athlete 
discussed the hardships of coping with the loss of ability due to illness and the emotional and psychological reactions to this struggle. Both loss and fragmentation of the self highlight this narrative (Sparkes, 1998).

Historically, the unanticipated exit from sport has been the focus of research on disengagement; however, there is a collection of research that examines the experiences of athletes who had a preconceived expectation of disengagement. Although it is often assumed that these athletes who are aware that their end is near have prepared in some way for the transition, the literature points to the fact that even though athlete's can have an expectation of leaving sport, this exit can be equally as difficult (Greendorfer \& Blinde, 1985; Mihovilovic, 1968; Werthner \& Orlick, 1986).

\section{Positive Disengagement Experiences}

Disengagement for athletics was once thought of as only a negative experience. However, certain studies have revealed that this is not always the case and this process can sometimes be a quite positive one (Allison \& Meyer, 1988; Coakley, 1983; Sinclair \& Orlick, 1993).

Using a sample of high-level Canadian athletes, Sinclair and Orlick (1993) found that athletes who encountered a smooth adjustment to life after sport tended to retire after sport related goals were achieved and/or achieved goals in sport. In a subsequent publication these authors reported five factors associated with positive adjustment from sport. These factors are: 1 ) planned transition; 2) voluntary transition; 3) achieving sport related goals; 4) having balance and options; and 5) a supportive environment (Sinclair \& Orlick, 1994). Coakley (1983) warned that just because an athlete disengages from sport, it should not be a given that emotional and psychological trauma will occur. In fact, adjustments are a necessary aspect of life, and it seems that most athletes handle the transition out of competitive sport in a relatively constructive 
manner. According to Coakley, the most influential factor that may affect the success of transition for the athlete is the availability of social resources for moving into new roles, especially those unrelated to athletics. As Coakley had addressed, disengagement from sport is not always met with emotional or psychological distress, but can in fact elicit positive feelings such as relief (Blinde \& Greendorfer, 1985). In a study investigating the retirement experiences of professional female tennis players, Allison and Meyer (1988) found that disengagement was a positive experiences, allowing for the reestablishment of more traditional roles and lifestyle. Contrary to much of the literature, junior athletes at the national level demonstrated a high overall life satisfaction after disengaging from hockey (Curtis \& Ennis, 1988).

\section{Self-Concept}

Self-concept is a description of oneself based on self-referenced experiences in one's environment (Marsh \& Shavelson, 1985; Sonstroem, 1998). When self-concept first became a popular topic in the 1960s and 1970s, many theories were produced with little empirical support (Fox, 1998). Self-concept was a unidimensional concept, often assessed by requiring participants to answer yes/no questions that were either positive or negative about them to produce a single self-concept score. This approach lacked the ability to provide a clear picture of the realities of self-concept (Fox, 1998). During the 1980s self-concept theory advanced towards a multidimensional structure of self-concept (Fox \& Corbin, 1989; Neemann \& Harter, 1986; Marsh \& Shavelson, 1985). Multidimensional self-concept incorporates separate domains or dimensions in addition to a global self-concept (Fox \& Corbin, 1989). The multidimensional model is hierarchically organized where perceptions of behavior are at the base, moving upwards to sub-areas of self-concept that are specific to either the academic or non-academic area, and then to the apex of global self-concept (Marsh \& Shavelson, 1985). In this model, the apex of 
global self-concept is seen as stable, but at the lower end of the model self-concept become increasingly situation specific and less stable. Implicit in the multidimensional model of selfconcept is the idea that the more experiences and situations that a person encounters, the more information the person has to build a self-description. In turn, the more successful in terms of performance the experiences are, the possibility exists for a positive evaluation of the self (Fox, 1989; Marsh, 1994). This idea is cyclical in nature. Therefore, over time a person's self-concept will be molded by successful experiences (Marsh, 1994).

Multidimensional self-concept theory postulates that one of the specific non-academic domains underlying global self-concept is physical self-concept (e.g., Fox, 1989; Harter, 1999; Marsh; 1994; Marsh \& Redmayne, 1994; Neeman \& Harter, 1986). In this model, if a person is successful at sport and evaluates his/her performance in a positive manner, this will strengthen this sub-domain of global self-concept.

Experiences of Athletes with Established Physical Self-Concepts

In the literature there are numerous studies conducted comparing the self-concepts (namely physical self-concepts) of athletes with other peer groups in an attempt to parcel out the possible differences in the formative experiences that make these groups different from each other. In a comparison of the self-concepts of female college athletes, physical education majors, general college students, and participants and non-participants in high school sports programs ( $N$ = 460), Vincent (1976) found that female education majors and those who had participated in high school sport programs had significantly higher self-concepts than the other groups. Specifically, when the variables of non-physical education major and participant in high school athletic program were held constant, college athletic participation was an influencing factor in the formation of self-concept. In a comparison of the difference of self-concepts between female 
high school and college tournament basketball players, Young (1981) reported significant differences between the two groups on self-satisfaction, behavior, physical self, moral-ethical self, and family self as well as total self-concept, with college players reporting more positive scores. These differences support the idea that there may be a possible educational and/or age effect in the development of self-concept.

In more recent studies, Welk, Corbin, and Lewis (1995) assessed the perceptions of high school athletes about sport competence, physical conditioning, strength, and physical attractiveness. It was found that high school athletes have strong physical self-perceptions compared to younger children and older adults, particularly in the areas of skill performance and conditioning. In a study comparing the multidimensional self-concepts of elite athletes and the general population many differences were discovered (Marsh, Perry, Horsely, \& Roche, 1995). Elite athletes had significantly higher scores on physical ability, social relationships, global esteem, and total self-concept. Although not significantly different, the general population had higher scores on spiritual and honesty self-concept and there were no reported differences between the groups on academic self-concept. Middle-aged adults who took part in a six-week exercise program exhibited a significantly improved physical self-concept and a decrease in psychosomatic complaints compared to a control group (Alfermann \& Stoll, 2000). In a study investigating the effect of a weight training class on stage of change and physical self-concept, Van Vorst, Buckworth, and Mattern (2002) found that there was a significant increase in physical activity and global physical self-concept for students in the preparation stage but not for those in the maintenance stage. However, all participants increased in physical strength and selfesteem. Similar results were found using a step dance class with male and female college 
students (Asci, 2002). After being enrolled in a 10-week step dance class, physical selfperceptions improved significantly for both genders compared to a control group.

\section{Athletic Identity}

The physical self-concept literature complements the idea of the existence of an athletic identity, one that the sport psychology literature has postulated for some time. Holland (1997) describes an identity as a self-understanding, self-objectification, or integration of information about the self. "Athletic identity” is seen as a strong affiliation with the athletic role, reflecting the level an individual assigns to oneself the role of an athlete as well as seeking out experiences that mesh with this role (Brewer, Van Raalte, \& Linder, 1993). Therefore, in relation to an athlete's self-schema, athletic identity is a cognitive structure that processes self-related information (Markus, 1977). Accordingly, an individual with a strong athletic identity will interpret an event (e.g., such as failing a college course) in relation to its impact on athletic functioning (e.g., being declared ineligible the next semester) to a greater degree that an individual with a weak athletic identity (e.g., being denied admission into graduate school) (Brewer et al., 1993).

Not only do athletes have a self-reference to being an athlete, the extent to which a person labels oneself an athlete may be influenced by powerful others such as parents, siblings, friends, coaches, and teachers designating it as a social role as well (Heyman, 1987). Throughout the literature, athletic identity has been described as a double-edged sword, having the possibility of a positive impact on athletic functioning but also having the possibility of a negative impact on identity formation, career planning, and retirement (Brewer et al., 1993; Ogilvie \& Howe 1986; Remmer, Tongate, \& Watson, 1978). Taylor and Ogilvie (2001) suggested that the disengagement process from athletics as well as the ensuing transitions that follow may be 
hindered when the athlete in question draws a high degree of identity from the athletic role. More specifically, research conducted with the Athletic Identity Measurement Scale (AIMS; Brewer, et al., 1993) found that athletic identity may decrease from the freshman to senior year in college due to the variety of activities and experiences outside of sport that athletes are introduced to at the university (Wiechman \& Williams, 1997). This idea is in contrast to previous research that found that the athletic role becomes more salient throughout college, with most incoming college students already having a well-established identity as a athlete (Adler \& Adler, 1991). These findings suggest that athletic identity may correlate positively with age in high school athletes where freshman high school athletes may have a lower identity than seniors and then with increasing age and athletic experiences may reach levels found with college freshman (Wiechman \& Williams, 1997).

Potential Benefits of a Strong Athletic Identity

Being know as an athlete and highly defining yourself as one, can have many potential benefits associated with a strong, well-developed, athletic identity (Blinde \& Greendorfer, 1985; Brewer, et al., 1993; Dollinger, 1996). A major benefit of athletic identity is its impact on the development of a positive self-identity through sports participation (McPherson, 1980). It gives the athlete a chance to build a positive sense of self through successes on the field of play. Through in-depth interviews with elite-level athletes, Werthner and Orlick (1986) reported that a strong identification with the athletic role had a positive effect on athletic performance because it arose out of commitment to the athlete's sport. Marsh (1993) found that the effects of high school sports participation are quite positive with few, if any, negative effects and can be generalized across individual characteristics such as race, social economic status, sex, and ability level; school size, and sport climate. From a life-long enjoyment of exercise perspective, a strong 
athletic identity that is developed through competitive sports participation can be influential in the maintenance of exercise behaviors throughout the lifespan (Anderson \& Cychosz, 1994). Potential Problems of a Strong Athletic Identity

Although there are potential benefits of having a well-developed, strong athletic identity, the focus of the disengagement literature has been on the problems associated with a high athletic identity, and research has supported this focus (Brewer, 1993; Grove et al., 1997; Murphy, Petitpas, \& Brewer, 1996). The potential risks of a strong athletic identity include emotional difficulties encountered in disengagement from sport through deselection, serious injury, and retirement (Person \& Petitpas, 1990; Taylor \& Ogilvie, 2001). The more an athlete identifies with the role of an athlete, as well as failing to explore other roles, has been shown to delay the career development of intercollegiate athletes (Grove et al., 1997; Murphy et al., 1996).

One’s level of athletic identity can greatly influence an athlete's response to a serious injury. An athlete with a strong athletic identity may experience emotional difficulties as a result of decreased participation stemming from a serious injury (Heyman, 1986; Person \& Petitpas, 1990; Sparkes, 1998; Weiss \& Troxel, 1986). The level of identification with the athletic role seems to be one of the major factors in predicting an athlete's response to injury. In a study conducted with only recreational athletes who as a whole did not highly identify with the athletic role, there was no significant correlation between athletic identity and injury (Green \& Weinberg, 2001). However, in some instances, just imagining incurring a serious injury can illicit a negative emotional response in athletes (Brewer, 1993). In Brewer’s study, a strong and exclusive athletic identity was related to athletes' affective response to both hypothetical and actual injuries. Moreover, depression was positively related to athletic identity for the athletes who imagined sustaining an injury. 
As stated in the previous section, an athlete's level of athletic identity has been shown to influence the emotional and psychological response when experiencing the termination of the athletic role in both qualitative and quantitative studies (Ballie \& Danish, 1992; Blinde \& Greendorfer, 1985; McPherson, 1980; Taylor \& Ogilvie, 2001; Werthner \& Orlick, 1986). Individuals whose self-identity is strongly influenced by an athletic role may lack the necessary social support systems for a smooth transition after retirement (Ballie \& Danish, 1992; Taylor \& Ogilvie, 2001). Athletic identity is also positively related to the duration of psychological adjustment needed as a result of the termination process (Brewer, 1993; Grove et al., 1997; Werthner \& Orlick, 1986). Grove et al., (1997) found that athletic identity was positively related to the amount of time it took athletes to emotionally, socially, and occupationally adjust to the role of non-athlete.

Athletic identity can influence how much an athlete prepares for the role as a non-athlete (Grove et al., 1997; Murphy et al., 1996; Wiechman \& Williams, 1997). In these instances, the less planning associated with a post-athletic career, the more difficulty adjusting to the new role of non-athlete may ensue (Murphy et al., 1996). More specifically, athletic identity was positively correlated with anxiety about career exploration and decision-making after retirement and negatively correlated with the amount of pre-retirement career planning (Grove et. al., 1997). High school students with the expectation of playing college or a professional league, on average, exhibited a strong athletic identity; in turn, there is the possibility that various transitional problems may arise when athletic involvement stops (Wiechman \& Williams, 1997). 


\section{Transition and Adjustment to College}

\section{Theories of Transition and Adjustment}

Schlossberg (1981) contends that a transition occurs if an event or non-event results in a change in assumptions about oneself and the world therefore requiring a corresponding change in one's behavior. Contained in the literature, there are a variety of theories attempting to explain the transition experiences of individuals such as individual variability theory (e.g., Neugarten 1979), lifespan theory, (e.g., Danish, 1981), stage theory (e.g., Erikson, 1950), and transitional theory (e.g., Lowenthal \& Chiriboga, 1975; Schlossberg, 1981). What separates Schlossberg's (1981) theory of adaptation to transition from the others is that it encompasses the transition experience as well as subsequent adaptation. It provides a rubric to help researchers understand how specific features and variables can influence transition and adaptation (Swain, 1991). Moreover, this model accounts for the wide variability and diversity of transitional experiences found between individuals. In this model, there are three important factors that can interact to influence and/or mediate the transition experience and subsequent adaptation for each individual.

The three components that are provided in this rubric and are most influential in this model of adaptation are 1) characteristics of the transition itself, 2) characteristics of the pretransition and post-transition environments, and 3) characteristics of the individual (Schlossberg, 1981). For a high school senior transitioning to college, the characteristics of the transition (i.e., leaving home and going to college) include variables such as role change, the positive/negative impact, perceptions of control of decision-making, time appropriate decision, onset, duration, and level of stress encountered. Characteristics of the pre-transition (i.e., high school and home life) and post-transition (i.e., the university) environments include variables such as interpersonal support systems, institutional supports, and physical setting. Characteristics of the individual 
(i.e., first semester college freshman) include variables such as psychosocial competence, gender, age, state of health, race/ethnicity, socioeconomic status, value orientation, and previous experience with similar transitions (Schlossberg, 1981). These factors coalesce to shape the adaptation experience that can be influenced by the disparity between the individual's resources and deficits as well as differences between pre-transition and post-transition environments (Schlossberg, 1981). Schlossberg's model represents a theoretical framework to evaluate all kinds of transitions, positive or negative, mundane or dramatic, while providing insight into what accounts for differences in time for the same person or the differences between two individuals as well as what mechanism might be responsible for making the transition a positive or negative one or why adaptation is easy for some individuals while difficult for others.

Schlossberg’s (1981) model of adaptation has been used in sport to predict as well as investigate transition out of athletics (Pearson \& Petitpas, 1990; Swain, 1991). Pearson and Petitpas (1990) used Schlossberg's model to provide a framework to predict the transition out of sport. Their prediction was that it will be most difficult for athletes who: a) have most exclusively based their identity on athletic performance; b) have the greatest gap between level of aspiration and ability; c) have had the least prior experience with similar transitions; d) are limited in their ability to adapt to change because of emotional and/or behavioral deficits; e) are limited in their ability to establish and maintain supportive relationships; and f) must deal with the transition in a context lacking material and emotional resources that could be helpful. Research conducted since these predictions have provided some support for this model (e.g., Murphy et. al., 1996; Perna et. al., 1999; Webb et. al, 1998). Swain (1991), using a qualitative method, gathered information about the experiences of 10 participants whom voluntarily withdrawn from competitive sport. It was found that the transitional experiences of these athletes 
were relevant to and in support of Schlossberg's theory. Each of the three components was supported, specifically the coping resources of the individual, concurrent stress, and commitments and values, were highlighted during the interview process (Swain, 1991).

\section{Developmental Theories}

Relying on Schlossberg's theory alone cannot account for a full explanation of the experiences of high school students transitioning to college. To gain a better picture of the experience, developmental task theories must also be examined. These theories are of particular importance to this population because of the developmental stages that must be accomplished at time in a person's life such as identity versus role confusion and intimacy versus isolation (Erikson, 1950). As in the transition literature, there is a vast amount of theory postulated to account for the development of an individual from an adolescent to an adult (Chickering, 1981; Farnsworth, 1966; Havighurst, 1952; Medalie, 1981). During the last two decades there has been less of an emphasis on the development of new transitional theories and more of a focus on testing the applicability of the theories on a variety of student populations (e.g. Chickering, 1999; Harris, 2003; Taub, 1997).

One of the most influential theories of college adjustment in both theory and practice is Arthur Chickering's (1969) model of student development, which was revised in 1993 by Chickering and Reisser. Chickering and Reisser (1993) propose a student’s psychosocial development surrounds seven vectors that link the experience of college to personal development. These seven vectors are: 1) achieving competence; 2) managing emotions; 3) becoming autonomous; 4) establishing identity; 5) developing mature interpersonal relationships; 6) clarifying purposes; and 7) developing integrity. While this model has been widely embraced by student affairs and retention professionals, there is another model (i.e., Medalie, 1981) that 
better incorporates the experiences of regular students and retired athletes experiences in the first year of college.

Medalie (1981) examined the four-year undergraduate college experience and established a model that focused on the developmental tasks that needed to be successfully addressed and accomplished to grow as a person and be ready for the world after college is completed. This developmental model has be labeled as a mini-life cycle and each year in school has a central developmental task that needs to be accomplished. These central tasks are characterized as: 1) divestment in old roles and the investment of new roles during the freshman year transition from home to college; 2) consolidation of the separation from home and choice of new interests and goals during the sophomore year; 3) mastery of and commitment to work during the junior year; and 4) the anticipation of the future during the senior year (Medalie, 1981).

When concentrating only on the developmental tasks of first year students, Medalie’s (1981) mini-life cycle postulates it as a period of divestment in old roles and investment into the new roles of college life for all students no matter the age, gender, or any other demands in addition to those as a student. This experience includes mourning the losses of growing up, saying goodbye to old support systems, making new attachments, and coping with the role of student. The quality of an individual's development depends on how successful these developmental tasks are confronted and accomplished (Medalie, 1981). These tasks can produce an anxious response that can be defended against by suboptimal adaptive solutions such as avoidance, procrastination, work compulsion, or denial. For the first year student who has fragile self-esteem, academics can be seen as the only method of success, leading to the development of a fantasy of perfection that cannot be attained. Medalie suggests that the readiness to accept some blows to academic ego is an important asset to be had during this time of transition. 
Undoubtedly, the first year of college is an important transitional time for an individual to become independent and grow as a person by successfully adapting to college through accomplishment of the divestment/investment developmental task.

Schlossberg's theory of adaptation to transition (1981) combined with Medalie's minilife cycle theory helps provide a clearer picture to conceptualize the specific transition from high school to college that these students are experiencing. Other researchers agree that the freshman year is generally acknowledged as a somewhat stressful situation and a time of social adjustment (Dunkel-Schetter \& Lobel, 1990; Oppenheimer, 1984). During this important transition, firstyear students face many social challenges such as moving away from home and the support system found there, as well as intellectual challenges such as the academic curriculum and overall college environment (Sher, Wood, \& Gotham, 1996).

\section{Influences on Transition \& Adjustment}

Research has shown that an individual's transition from high school to college can be a positive and/or a negative experience in the beginning months. It is a period of divestment in old roles and investment in new ones (Medalie, 1981). In fact, it has been found that adjustment to college stress declines across the span of the four years as a function of adaptation (Sher, Wood, \& Gotham, 1996). Pre-college concerns about losing existing friendships and making new friends can mediate both self-esteem and friendship satisfaction (Paul \& Kelleher, 1995), which can in turn increase or decrease life satisfaction. Some common sources of problems for new college students include a sub-par academic record in high school, social and interpersonal distractions, family crises, financial stress, confused career direction, and health problems (Mucowski, 1984). Baker and Schultz (1992) in examining the experiences of freshman students found that those with low levels of adjustment tended to 1) not to perform as well academically; 
2) be more likely to seek out campus counseling services; 3) have a higher dropout rate; and 4) report less overall satisfaction with the college experience. It has been found that students who adjust well to the college environment are those who are academically ready to persist, however, less than half of freshman students have a clear sense of their future in college (McGrath \& Braunstein, 1997). As previously addressed, some, if not all of these sources can be influenced by a strong athletic identity and/or sports participation. This transition phase can be met with emotional disturbances such as, but not limited to: loneliness, homesickness, and friendsickness (Morris, 1997; Paul \& Brier, 2001), grief (Vickio, 1990) and substance abuse/alcohol-related risk behaviors (Hildebrand, Johnson, \& Bogle, 2001).

Martin, Swartz-Kulstad, and Madison (1999) believed that research on the variables of psychosocial disturbance form three distinct categories: social (e.g., parental influences, social adjustment), personal-emotional (e.g., emotional adjustment, coping style), and institutional (e.g., attachment to the institution). In turn, these variables have great accuracy in predicting college student adjustment (Baker \& Siryk, 1989). Lopez, Campbell, and Watkins (1986) investigated self-reported depression and psychological separation in response to adjustment to college for both males and females and found a negative correlation between psychological separation from parents and depression for females. However, males exhibited higher independency from parents and no significant relationships between depression and college adjustment were found. The impact of an individual's transition to college, in addition to the impact of disengagement from organized sport could greatly influence the emotional response of first semester college students and affect the retention of these students at the university level. 


\section{Athletic Participation and its Influence on the College Experience}

In Coleman’s (1959) seminal study on adolescent status systems, it was found that athletic prowess was the most important criterion for increased status in high school. This finding was revisited sixteen years later by Eitzen (1975) and the data once again pointed to strong support that athletic prowess still continued to prevail. Even though Eitzen's study is now over 29 years old, what is to say that athletic status is still not an important determinant of high status in high school? More importantly, how might this coveted status, gained through athletic participation in high school influence subsequent college experiences? To answer this, we must first look at participant motivation in youth sport. Gill, Gross, and Huddleston (1983) studied the reasons for participation in male and female youths, ages 8-18 and it was found that for both genders, achievement/status, team, fitness, energy release, situational factors, skill development, friendship, and fun were all important aspects of motivation. Specifically, males placed more importance on achievement/status than females. Therefore, even after 24 years since Coleman's study, status is still an important factor for participation for males.

Looking at the larger picture of participation in high school sport, Marsh (1993) examined the effects of sport participation during the last two years of high school using data collected from the High School and Beyond between 1980 and 1984. The antecedents of participation (sophomore year) include being male, the expectation of attending college, social economic status, being black, and attending a small school. The largest positive associations with sport participation are for social self-concept, educational aspirations, academic self-concept, general self-concept, school grades, and parental educational aspirations (Marsh, 1993). The consequences of sport participation are all positive and include social self-concept, academic self-concept, educational aspirations two years after high school, attending a university, 
educational aspirations in the senior year, being on an academic track, school attendance, taking academic courses, taking science courses, time spent on homework, parental involvement, parental educational aspirations, taking math courses, and taking honors courses. It is important to reiterate that sport participation had no negative effects for either gender. The effects of participation in sport are mediated by four senior outcomes: 1) parental aspirations; 2) academic self-concept; 3) educational aspirations; and 4) social self-concept (Marsh, 1993). In contrast to Coleman's findings, this study found that sport adds to time, energy, and commitment to academic pursuits. One finding of this study, participation's potential to enhance identification with the school, may affect the developmental task of divestment proposed by Medalie (1981).

\section{Summary}

While there have been numerous theories and studies focusing on both disengagement from sport and the impact of a strong athletic identity, there has been little research or application to the high school athlete who retires from sport and attends first semester college as a non-athlete (e.g. Allison \& Meyer, 1988; Sinclair \& Orlick, 1993; Wiechman \& Williams, 1997). Therefore, much of what might occur in the transitional experience of this disengaged athlete must be gleaned from studies and theories that focus on elite and college athletes. In this respect, the research is ripe with qualitative and quantitative research studies. However, the research is equivocal in nature: some studies pointing to the positives of both disengagement and a strong athletic identity, while others relying on the negative aspects of both disengagement and a strong athletic identity. For college and elite athletes who have the expectation of leaving sport, the actual disengagement can be as difficult for them as for athletes who are suddenly faced with the end of a career (Greendorfer \& Blinde, 1985; Werthner \& Orlick, 1986). This experience could also be found at the high school level as well. 
While high school athletics has been found to be quite a positive life experience for most who participate (Marsh, 1993), there is the possibility that athletic participation might hinder adjustment after high school sports participation is finished. There are a variety of theories that focus on the transition to college as a time of change and independence. Specifically, Medalie (1981) conceptualizes the first year of college as a divestment from the old roles as a high school student to the investment in the new roles of college student and greater independence. Included in this divestment of old roles must be the role as a competitive athlete (in the respect to varsity athletics) for high school athletes who do not play at the college level. Ex-athletes who divest in this role and find new, more appropriate ones, would seen to adjust better than those ex-athletes who cannot find more suitable roles. 
College Adjustment 68

\section{APPEDNIX E}

Review of Literature References 


\section{References}

Adler, P.A., \& Adler, P. (1991). Backboards and blackboards. New York: Columbia University.

Alfermann, D., \& Stoll, O. (2000). Effects of physical exercise on self-concept and wellbeing. International Journal of Sport Psychology, 30, 47-65.

Baker, R.W., \& Schultz, K.L. (1992). Measuring expectations about college adjustment. NACADA Journal. 12, 23-32.

Bianco, T. \& Eklund, R.C. (2001). Conceptual considerations for social support research in sport and exercise settings: The case of sport injury. Journal of Sport \& Exercise Psychology, 23, 85-107.

Brewer, B.W. (1993). Self-identity and specific vulnerability to depressed mood. Journal of Personality, 61, 343-364.

Dollinger, S.J. (1996). Autophotographic identities of young adults: With special reference to alcohol, athletics, achievement, religion, and work. Journal of Personality Assessment, 67, 384-398.

Fox, K.R. (1998). Advances in the measurement of the physical self. In J.L. Duda (Ed.), Advances in sport and exercise psychology measurement (pp. 295-310). Morgantown: Fitness Information Technology.

Fox, K.R., \& Corbin, C.B. (1989). The Physical Self-Perception Profile: Development and preliminary validation. Journal of Sport \& Exercise Psychology, 11, 408-430.

Gill, D.L., Gross, J.B., \& Huddleston, S. (1983). Participation motivation in youth sports. International Journal of Sport Psychology, 14, 1-14.

Green, S.L. \& Weinberg, R.S. (2001). Relationships among athletic identity, coping 
skills, social support, and the psychological impact of injury in recreational participants. Journal of Applied Sport Psychology, 13, 40-59.

Harris, L.L. (2003). Integrating and analyzing psychosocial and stage theories to challenge the development of the injured collegiate athlete. Journal of Athletic Training, 38(1), 75-82.

Harter, S. (1999). The construction of the self. New York: The Guilford Press.

Heyman, S.R. (1986). Psychological problem patterns found with athletes. The Clinical Psychologist, 39, 68-71.

Heyman, S.R. (1987). Counseling and psychotherapy with athletes: Special considerations. In J.R. May \& M.J. Asken (Eds.), Sport psychology: The psychological health of the athlete (pp. 135-156). New York: PMA.

Holland, D. (1997). Selves as cultured. In R.D. Ashmore and L. Jussim (Eds.), The self and identity: Fundamental issues (pp. 160-190). New York: Oxford.

Lavallee, D., \& Andersen, M.B. (2000). Leaving sport: Easing career transitions. In M.B. Andersen (Ed.), Doing sport psychology (pp. 249-260). Champaign, IL: Human Kinetics.

Lopez, F.G., Campbell, V.L., \& Watkins, C.E. (1986). Depression, psychological separation, and college adjustment: An investigation of sex differences. Journal of Counseling Psychology, 33, 52-56.

Lowenthal, M.F., \& Chiriboga, D. (1975). Responses to stress. In M.F. Lowenthal, M. Thurnher, and D. Chiriboga (Eds.), Four stages of life: A comparative study of women and men facing transitions. San Francisco: Jossey-Bass.

Markus, H. (1977). Self-schemata and processing information about the self. Journal of 
Personality and Social Psychology, 35, 63-78.

Marsh, H.W. (1993). The effects of participation in sport during the last two years of high school. Sociology of Sport Journal, 10, 18-43.

Marsh, H.W. (1994). The importance of being important: Theoretical models of relations between specific and global components of physical self-concept. Journal of Sport \& Exercise Psychology, 16, 306-325.

Marsh, H.W., Perry, C., Horsely, C., \& Roche, L. (1995). Multidimensional selfconcepts of elite athletes: How do they differ from the general population? Journal of Sport \& Exercise Psychology, 17, 70-83.

Marsh, H.W., \& Redmayne, R.S. (1994). A multidimensional physical self-concept and its relation to multiple components of physical fitness. Journal of Sport \& Exercise Psychology, 16, 45-55.

Marsh, H.W. \& Shavelson, R. (1985). Self-concept: Its multi-faceted hierarchical structure. Educational Psychologist, 20, 107-123.

McGrath, M., \& Braunstein, A. (1997). The prediction of freshman attrition: An examination of the importance of certain demographic, academic, financial, and social factors. College Student Journal, 31, 396-407.

Mucowski, R.J. (1984). Some common problems of new students and sources of help. Journal of College Student Personnel, 24, 550-551.

Neemann, J., \& Harter, S. (1986). Manual for the Self-Perception Profile for College Students. Denver, CO: University of Denver.

Paul, E.L. \& Kelleher, M. (1995). Precollege concerns about losing and making friends 
in college: Implications for friendship satisfaction and self-esteem during the college transition. Journal of College Student Development, 36, 513-521.

Perna, F.M., Ahlgren, R.L., \& Zaichkowsky, L. (1999). The influence of career planning, race, and athletic injury and life satisfaction among recently retired collegiate male athletes. The Sports Psychologist, 13, 144-156.

Petitpas, A., Champagne, D., Chartrand, J., Danish, S., \& Murphy, S. (1997). Athlete’s guide to career planning. Champaign, IL: Human Kinetics.

Remmer, R., Tongate, F.A., \& Watson, J. (1978). Athletes: Counseling the overprivileged minority. Personnel and Guidance Journal, 56, 626-629.

Rosenberg, E. (1981). Gerontological theory and athletic retirement. In S.L. Greendorfer and A. Yiannakis (Eds.), Sociology of sport: Diverse perspectives (pp. 118-126). West Point, NY: Leisure Press.

Sonstroem, R.J. (1998). Physical self-concept assessment and external validity. Exercise and Sport Sciences Reviews, 26, 133-164.

Van Vorst, J.G., Buckworth, J., \& Mattern, C. (2002). Physical self-concept and strength changes in college weight training classes. Research Quarterly for Exercise and Sport, 73, 113-117.

Vincent, M.F. (1976). Comparison of self-concepts of college women: Athletes and physical education majors. The Research Quarterly, 47, 218-225.

Weiss, M.R., \& Troxel, R.K. (1986). Psychology of the injured athlete. Athletic Training, 21, 104-109.

Welk, G.J., Corbin, C.B., \& Lewis, L.A. (1995). Physical self-perceptions of high school athletes. Pediatric Exercise Science, 7, 152-161. 
Wiechman, S., \& Williams, J. (1997). Relation of athletic identity to injury and mood disturbance. Journal of Sport Behavior, 20(2), 199-210.

Young, M.L. (1981). Comparison of self-concepts of women high school and college tournament basketball players. Research Quarterly for Exercise and Sport 